OPEN ACCESS

Edited by:

Octavio Luiz Franco,

Universidade Católica de Brasilia,

Brazi

Reviewed by:

Semih Esin,

Università degli Studi di Pisa, Italy Timothy Arnold Paget,

University of Sunderland,

United Kingdom

*Correspondence:

Matthew J. Hardman

m.hardman@hull.ac.uk

Specialty section: This article was submitted to Antimicrobials, Resistance

and Chemotherapy,

a section of the journal

Frontiers in Microbiology

Received: 04 December 2017

Accepted: 11 June 2018

Published: 03 July 2018

Citation:

Wilkinson HN, Iveson S, Catherall P and Hardman MJ (2018) A Novel

Silver Bioactive Glass Elicits

Antimicrobial Efficacy Against

Pseudomonas aeruginosa and Staphylococcus aureus in an ex Vivo Skin Wound Biofilm Model.

Front. Microbiol. 9:1450

doi: 10.3389/fmicb.2018.01450

\section{A Novel Silver Bioactive Glass Elicits Antimicrobial Efficacy Against Pseudomonas aeruginosa and Staphylococcus aureus in an ex Vivo Skin Wound Biofilm Model}

\author{
Holly N. Wilkinson', Sammi Iveson ${ }^{1}$, Paul Catherall ${ }^{2}$ and Matthew J. Hardman ${ }^{1 *}$ \\ ${ }^{1}$ School of Life Sciences, University of Hull, Hull, United Kingdom, ${ }^{2}$ Theraglass Ltd., London, United Kingdom
}

Biofilm infection is now understood to be a potent contributor to the recalcitrant nature of chronic wounds. Bacterial biofilms evade the host immune response and show increased resistance to antibiotics. Along with improvements in antibiotic stewardship, effective new anti-biofilm therapies are urgently needed for effective wound management. Previous studies have shown that bioactive glass $(\mathrm{Bg})$ is able to promote healing with moderate bactericidal activity. Here we tested the antimicrobial efficacy of a novel BG incorporating silver (BgAg), against both planktonic and biofilm forms of the wound-relevant bacteria Pseudomonas aeruginosa and Staphylococcus aureus. BgAg was stable, long lasting, and potently effective against planktonic bacteria in time-kill assays (6-log reduction in bacterial viability within $2 \mathrm{~h}$ ) and in agar diffusion assays. BgAg reduced bacterial load in a physiologically relevant ex vivo porcine wound biofilm model; $P$. aeruginosa (2-log reduction) and $S$. aureus (3-log reduction). Bg ${ }^{\mathrm{Ag}}$ also conferred strong effects against $P$. aeruginosa biofilm virulence, reducing both protease activity and virulence gene expression. Co-culture biofilms appeared more resistant to $\mathrm{Bg}{ }^{\mathrm{Ag}}$, where a selective reduction in $S$. aureus was observed. Finally, $\mathrm{Bg}^{\mathrm{Ag}}$ was shown to benefit the host response to biofilm infection, directly reducing host tissue cell death. Taken together, the findings provide evidence that $\mathrm{Bg} A$ elicits potent antimicrobial effects against planktonic and single-species biofilms, with beneficial effects on the host tissue response. Further investigations are required to elucidate the specific consequences of $B G$ administration on polymicrobial biofilms, and further explore the effects on host-microbe interactions.

Keywords: biofilm, bioactive glass, wound healing, Pseudomonas aeruginosa, Staphylococcus aureus

\section{INTRODUCTION}

Breaches to the skin barrier must be repaired in a timely and efficient manner to prevent infection and wound persistence (Bjarnsholt et al., 2008). Unfortunately, healing often fails, leading to chronic, non-healing wounds. Chronic wounds affect millions of patients annually, with associated substantial costs to healthcare providers (Posnett and Franks, 2008; Gould et al., 2015). 
In recent years, one of the most discussed extrinsic contributors to wound chronicity has been the presence of infection, particularly critical colonization by pathogenic organisms existing as biofilms (Dow et al., 1999; James et al., 2008; Wolcott et al., 2015). Biofilms are bacterial aggregates able to evade host responses and develop rapid pathogenicity (reviewed in Gellatly and Hancock, 2013; Flemming et al., 2016). They are encapsulated in self-produced extracellular polymeric substances (EPS), which provide a protective barrier against both host defenses and exogenous antibiotic treatments (Flemming and Wingender, 2010). Moreover, biofilms consist of heterogeneous communities which allows inter-specific transfer of metabolites and antimicrobial-resistance genes, thus increasing overall bacterial virulence (Leid et al., 2005; Mah, 2012). Sadly, wound infection is on the rise, with the prevalence of antibiotic-resistant bacterial strains and the persistence of biofilms contributing to the recalcitrant nature of chronic wounds (Velnar et al., 2009). Antibiotic resistance is not only a problem for wound management but a widespread threat to human health, claiming in excess of 50,000 lives in western society alone (O'Neill, 2014). Consequently, the implementation of antibiotic stewardship programs worldwide aim to prevent misuse thus reducing antibiotic resistance and improving patient outcome (Bowler, 2018).

Bioactive materials are a concept first introduced by L. L. Hench, who stated that the main requirement of a bioactive material was to elicit a biological response at the interface between the material and the living tissue (Hench, 2006). Bioactive glass (BG) has emerged as one such bioactive material, which has the potential to promote dental and bone repair. BG compositions can include compounds with known prohealing effects (e.g., $\mathrm{CaO}, \mathrm{SiO}_{2}, \mathrm{P}_{2} \mathrm{O}_{5}$, and $\mathrm{MgO}$; Lin et al., 2012). BGs bond compatibly to tissues via dissolution and precipitation reactions that actuate surface ion exchange. In damaged bone tissue, $\mathrm{BG}$ ion release increases $\mathrm{pH}$, causing the formation of a hydroxycarbonate apatite (HCA) interface layer, which mimics the type of scaffold that would naturally form during tissue repair (Hench, 2006). This HCA interface then promotes cell migration, osteoprogenitor differentiation (Jones, 2013; Miguez-Pacheco et al., 2015) and ultimately accelerates bone matrix reformation (as assessed in Maçon et al., 2017). Interestingly, elevated alkalinity can provide a bactericidal environment, thus BG alone may have antibacterial effects (Zehnder et al., 2006). BGs can also be used as a substrate for incorporating known antimicrobials, such as metal nanoparticles (Gholipourmalekabadi et al., 2016).

Silver (Ag) and silver nanoparticles (AgNPs) exhibit potent antimicrobial efficacy against a range of bacterial species (Ruparelia et al., 2008), including antibiotic-resistant strains (Mekkawy et al., 2017; Tiwari et al., 2017a,b) and established biofilms (Ueno et al., 2016) in experimental settings. In the clinic, the evidence for silver efficacy is less robust, underpinning variability in clinical use (Rodriguez-Arguello et al., 2018). Incorporating $\mathrm{Ag}$ and AgNPs into BG has been suggested as a potential alternative to antibiotics for reducing infection in a range of clinical applications (Zhao et al., 2015). Theraglass ${ }^{\mathrm{TM}}$ (Theraglass Ltd., United Kingdom) is a novel, highly bioactive, binary $\left(\mathrm{SiO}_{2}\right.$ and $\mathrm{CaO}$ ) sol-gel derived $\mathrm{BG}$ (Saravanapavan and Hench, 2001; Bellantone et al., 2002; Poologasundarampillai et al., 2014; Maçon et al., 2015). Advantages of sol-gel derived BG over more traditional melt-derived BG include easier manufacturing processes and higher purity (Saravanapavan and Hench, 2001). Theraglass ${ }^{\mathrm{TM}}$ also exhibits a larger surface area to volume ratio than other BG formulations, which may convey higher overall bioactivity (Maçon et al., 2015). One formulation of Theraglass ${ }^{\mathrm{TM}}$ also incorporates silver $(\mathrm{AgO})$ hence it maintains high potential as an antimicrobial therapeutic.

In the present study, we aimed to elucidate the antimicrobial and anti-biofilm efficacy of a novel, highly bioactive, binary solgel derived AgO-functionalized BG (Theraglass ${ }^{\mathrm{TM}}$ ) against the opportunistic wound pathogens Pseudomonas aeruginosa and Staphylococcus aureus.

\section{MATERIALS AND METHODS}

\section{Bioactive Glass Formulations}

The elemental composition of Theraglass ${ }^{\mathrm{TM}}$ by $\mathrm{mol} \%$ is 70 $\mathrm{SiO}_{2}: 30 \mathrm{CaO}$, while Theraglass ${ }^{\mathrm{TM}} \mathrm{Ag}$ contains $70 \quad \mathrm{SiO}_{2}: 28$ $\mathrm{Ca}: 2 \mathrm{AgO}$ by mol\%. Topical treatments were prepared from powders containing BG (Theraglass ${ }^{\mathrm{TM}}$; "Bg") and BG containing silver (Theraglass ${ }^{\mathrm{TM}} \mathrm{Ag}$; "Bg ${ }^{\mathrm{Ag}}$ "), mixed with a vehicle (Nivea, Beiersdorf) to produce BG preparations at a $20 \%(\mathrm{w} / \mathrm{v})$ working concentration. A 2\% (w/v) silver (AgO) control ("Ag") was included, at the equimolar concentration of $\mathrm{AgO}$ in $\mathrm{Bg}^{\mathrm{Ag}}$, by mixing the vehicle with AgO. For all experiments, except stability and kinetics testing, treatments were prepared and applied fresh (i.e., immediately post-mixing).

\section{Bacterial Cell Culture}

Clinical reference strains of $P$. aeruginosa (NCTC 10781) and $S$. aureus (NCTC 13297) were chosen in this study because of their direct relevance in chronic wound infection (Price et al., 2009). Bacterial stocks stored at $-80^{\circ} \mathrm{C}$ in glycerol were streaked onto Mueller-Hinton agar (MHA; Oxoid) plates and incubated for $24 \mathrm{~h}$ at $37^{\circ} \mathrm{C}$ to produce viable colonies. Overnight $(\mathrm{O} / \mathrm{N})$ cultures were prepared by incubating a single bacterial colony in $10 \mathrm{ml}$ Mueller-Hinton broth (MHB; Oxoid) for $16 \mathrm{~h}$ at $37^{\circ} \mathrm{C}$ with $140 \mathrm{rpm}$ shaking (Labnet 211DS shaking incubator, Labnet International). For all assays, $\mathrm{O} / \mathrm{N}$ cultures were adjusted to 0.5 on the McFarland turbidity scale as described in Balouiri et al. (2016) unless otherwise stated. Briefly, bacterial cultures were diluted in $0.85 \%(\mathrm{w} / \mathrm{v})$ sterile saline and adjusted to an optical density (OD) of $0.08-0.12$ at $625 \mathrm{~nm}$ using a spectrophotometer (Jenway 7310, Cole-Parmer). Adjusted bacterial suspensions were further diluted 1:150 in MHB to give starting concentrations between $5 \times 10^{5}$ and $1 \times 10^{6}$ colony forming units per $\mathrm{ml}(\mathrm{CFU} / \mathrm{ml})$, confirmed by spread plating on MHA.

\section{Agar Diffusion Testing}

Pseudomonas aeruginosa and S. aureus, adjusted to the turbidity scale described above, were spread onto MHA (200 $\mu$ l per plate). Sterile $1 \mathrm{~cm}^{2}$ pieces of Tegaderm ${ }^{\mathrm{TM}}$ pad (3M) were used to apply 
treatments (described above) to MHA plates. A vehicle control (Tegaderm $^{\mathrm{TM}}$ Pad and Nivea) was also included. Treatments ( $n=3$ per group) were incubated at $37^{\circ} \mathrm{C}$ for 24 and $48 \mathrm{~h}$. At the point of collection, plates were imaged with a Nikon camera (Finepix S5700, Nikon) and growth inhibition zones were measured in ImageJ v.1.6 (National Institutes of Health, $\mathrm{NIH}$ ). Agar diffusion tests were repeated in three independent experiments.

\section{Time-Kill Assays}

Adjusted cultures of $P$. aeruginosa and $S$. aureus in MHB were added to sterile universal tubes ( $5 \mathrm{ml}$ per tube) with $1 \mathrm{~g}$ of fresh cream treatment (described above). Tubes were incubated at $37^{\circ} \mathrm{C}$ with $140 \mathrm{rpm}$ shaking for $0.5,1,2,3,6$, and 24 -h timepoints. Upon collection, $100 \mu \mathrm{l}$ of bacterial broth was removed from each tube and added to $900 \mu \mathrm{l}$ Dey-Engley Neutralizing broth (DENB; Fluka, Sigma-Aldrich). The DENB was tested prior to use to ensure it neutralized the antimicrobial treatments under study (data not shown). Samples were serial diluted, plated on $\mathrm{MHA}$ in duplicate, and incubated for $24 \mathrm{~h}$ at $37^{\circ} \mathrm{C}$ to determine $\mathrm{CFU} / \mathrm{ml}$. The time-kill assay was repeated in three independent experiments.

\section{Stability and Kinetics Testing}

To test the stability of $\mathrm{Ag}, \mathrm{Bg}$, and $\mathrm{Bg}^{\mathrm{Ag}}$, preparations (described above) were incubated at $4^{\circ} \mathrm{C}$ and room temperature (RT) for 24-120 h. At each 24-h interval, treatments were collected for agar diffusion assays against $P$. aeruginosa and $S$. aureus (as above). To test the kinetics of antimicrobial soluble factor release, $\mathrm{Bg}$ and $\mathrm{Bg}^{\mathrm{Ag}}$ (1 g per tube) were incubated in tubes containing $5 \mathrm{ml}$ of Dulbecco's phosphate buffered saline (DPBS; Gibco, United Kingdom) at RT on a rocker over a period of 24-144 h, and collected at 24-h intervals. At each time point, supernatant (SN) was collected and replaced with fresh DPBS. Tegaderm ${ }^{\mathrm{TM}}$ Pad was soaked in collected SN and added to bacterial plates for agar diffusion testing.

\section{Biofilm Formation Tests}

Following our investigations of the antimicrobial efficacy of BG against planktonic bacteria, we tested the ability of BG to inhibit biofilm formation. Here, a standard 96-well microtiter plate assay was performed (as described in O'Toole, 2011). Briefly, $50 \mu \mathrm{l}$ of MHB was added to each well, with treatments serial diluted (twofold dilutions) down each row. P. aeruginosa, S. aureus, and co-cultures (50:50 mix of $P$. aeruginosa:S. aureus), adjusted to the $0.5 \mathrm{McF}$ arland standard and diluted as above, were added to each well (50 $\mu$ l per well). Plates were incubated under aerobic conditions at $37^{\circ} \mathrm{C}$ for $48 \mathrm{~h}$. After this time, plates were submerged in $\mathrm{dH}_{2} \mathrm{O}$ to remove planktonic bacteria, and $125 \mu \mathrm{l} 0.1 \%(\mathrm{w} / \mathrm{v})$ crystal violet was added to each well for $30 \mathrm{~min}$ to stain biofilms. Plates were washed in $\mathrm{dH}_{2} \mathrm{O}$ and dried $\mathrm{O} / \mathrm{N}$. To solubilize the crystal violet, $200 \mu \mathrm{l}$ of $30 \%$ acetic acid was added to each well and plate absorbance was measured at $570 \mathrm{~nm}$. Biofilm formation was categorized as in Christensen (1989) based on the ODs obtained above (see Table 1). The OD cut-off (ODc) was deduced as three standard deviations above the
TABLE 1 | Optical density classifications used to determine strength of biofilm production in biofilm formation assays.

\begin{tabular}{ll}
\hline $\mathbf{O D}_{495} \mathrm{~nm}$ value & Classification \\
\hline$\leq 0.04$ & Non-adherent \\
$>0.04$ and $\leq 0.08$ & Weak biofilm \\
$>0.08$ and $\leq 0.16$ & Moderate biofilm \\
$>0.16$ & Strong biofilm \\
\hline
\end{tabular}

mean OD of the negative control. Biofilms were then classified as follows:

$\mathrm{OD} \leq \mathrm{ODc}=$ non-adherent

ODc $<$ OD $\leq 2 \times$ ODc $=$ weak biofilm

$2 \times$ ODc $<$ OD $\leq 4 \times$ ODc $=$ moderate biofilm

$4 \times \mathrm{ODc}<\mathrm{OD}=$ strong biofilm

\section{Ex Vivo Porcine Wound Biofilm Model}

To test the effects of BG on established biofilms, an ex vivo porcine wound biofilm model was employed (as in Wilkinson et al., 2016). Adjusted bacteria were added in $20 \mu \mathrm{l}$ droplets to sterile nylon filter membranes (Merck-Millipore) on MHA and biofilms were left to form at the air-filter interface for $72 \mathrm{~h}$ at $37^{\circ} \mathrm{C}$. Every $24 \mathrm{~h}$, membrane biofilms were transferred to fresh MHA plates. For co-culture experiments, planktonic cultures of $P$. aeruginosa and $S$. aureus were mixed in a 1:1 ratio and added to filter membranes as above. Next, fresh porcine skin, collected under University ethical approval (FEC_21_2017) from a local abattoir, was held in high glucose Dulbecco's Modified Eagle's Medium (HG DMEM, Gibco) containing 10\% (v/v) fetal bovine serum (FBS; Gibco), $100 \mathrm{U} / \mathrm{ml}$ penicillin-streptomycin (Gibco), $10 \mu \mathrm{g} / \mathrm{ml}$ gentamicin and $2.5 \mu \mathrm{g} / \mathrm{ml}$ Amphotericin B (both Sigma-Aldrich). The subcutaneous adipose tissue was removed; the skin was washed in Hank's Balanced Salt Solution (HBSS, Sigma-Aldrich) containing $2 \times$ Antibiotic-Antimycotic (Gibco), and washed in DPBS prior to wounding.

The porcine skin was cut into $1 \mathrm{~cm}^{2}$ squares; wounds were created by complete removal of the epidermis, and were treated with established biofilms. Absorbent pads were soaked in HG DMEM containing supplements (as above). A filter membrane was placed between the absorbent pads and each porcine biofilm explant to allow nutrient transfer to the skin without submersion (modified from Stojadinovic et al., 2013). The skin was cultured at $37^{\circ} \mathrm{C}$ and $5 \% \mathrm{CO}_{2}$ for $24 \mathrm{~h}$ to allow biofilm attachment. Treatments were then added to each biofilm (as described above), including non-treated biofilm controls and uninoculated porcine wound controls.

\section{Porcine Wound Biofilm Collection}

Following $24 \mathrm{~h}$ of incubation, porcine ex vivo biofilm explants were bisected at their midpoint, with half wounds collected for viability counts (CFU/ml), histological analysis, extracellular protease production (via a colorimetric assay and zymography), and virulence factor expression. 


\section{Viability Counts}

Tissue was cut into pieces $(<1 \mathrm{~mm})$ and vortexed in tubes containing $1 \mathrm{ml} \mathrm{MHB}$ and $5 \mathrm{ml}$ sterile borosilicate glass beads (Sigma-Aldrich) for $3 \times 10 \mathrm{~s}$ pulses. From each tube, $100 \mu \mathrm{l}$ of re-suspended bacteria was removed and serial diluted in $900 \mu \mathrm{l}$ DENB, with $100 \mu \mathrm{l}$ of each dilution spread on MHA plates (for single species enumeration) or Cetrimide agar (Oxoid) and Mannitol Salt agar (Oxoid) for co-culture colony counts. Plates were incubated at $37^{\circ} \mathrm{C}$ for $24 \mathrm{~h}$. Colonies were enumerated to give $\mathrm{CFU} /$ sample.

\section{Biofilm Visualization}

Samples embedded in optimal cutting temperature media (OCT, CellPath) were cryo-sectioned at $10 \mu \mathrm{m}$. Gram-Twort, Acridine Orange (AO; Sigma-Aldrich), and Concanavalin A (ConA, Thermo Fisher Scientific) staining were used to visualize porcine wound biofilm load. A modified Gram-Twort stain was carried out. Here, sections were fixed in methanol at $-20^{\circ} \mathrm{C}$ for $10 \mathrm{~min}$, stained with Crystal Violet and Gram's Iodine solutions (both Sigma-Aldrich), differentiated in $2 \%(\mathrm{v} / \mathrm{v})$ acetic-alcohol and counterstained with a $0.2 \%(\mathrm{w} / \mathrm{v})$ neutral red and $0.2 \%(\mathrm{w} / \mathrm{v})$ fast green (9:1) solution (Sigma-Aldrich). Sections were differentiated again, rapidly dehydrated in $100 \%$ ethanol and mounted with Pertex $^{\circledR}$ mounting medium (CellPath). Images were captured at $\times 100$ magnification on a Nikon E400 microscope with SPOT camera (SPOT imaging). For fluorescent visualization, methanolfixed sections were incubated in AO solution $(2 \mathrm{mg} / \mathrm{ml})$ for $5 \mathrm{~min}$ at $\mathrm{RT}$ and rinsed in $\mathrm{dH}_{2} \mathrm{O}$, or incubated in ConA $(50 \mu \mathrm{g} / \mathrm{ml})$ at $4^{\circ} \mathrm{C} \mathrm{O} / \mathrm{N}$ and counterstained with DAPI (Thermo Fisher Scientific). Mowiol 4-88 (Sigma-Aldrich) containing DABCO (Thermo Fisher Scientific) was used for mounting. Fluorescent images were taken on a Zeiss Axio Vert. A1 microscope with AxioCam| cml camera (Carl Zeiss Microscopy Ltd) at $\times 40$ magnification. Gram-Twort biofilm thickness analysis was performed in ImageJ v.1.6 (NIH).

\section{Zymography}

Bacteria isolated from treated porcine biofilms via glass bead dissociation (described above) were centrifuged at 10,000 $\times g$ and $4^{\circ} \mathrm{C}$ for $10 \mathrm{~min}$. The $\mathrm{SN}$ fraction (containing extracellular proteases) was removed, sterile-filtered $(0.22 \mu \mathrm{m}$, MerckMillipore) and stored at $-80^{\circ} \mathrm{C}$ until use. Gelatin zymography was performed to assess extracellular protease activity. SN was run on $7.5 \%$ acrylamide gels containing $0.2 \%(\mathrm{w} / \mathrm{v})$ porcine skin gelatin (Oxoid) in non-reducing conditions. Precision Plus Protein ${ }^{\mathrm{TM}}$ Kaleidoscope $\mathrm{TM}^{\mathrm{TM}}$ Prestained Protein Standards (Bio-Rad) were used to determine molecular weights of the separated proteins in the gel. An MMP9 standard (Thermo Fisher Scientific) was included as an internal control. Gels, washed in $2.5 \%(\mathrm{v} / \mathrm{v})$ Triton X-100, and incubated in gelatinase resolving buffer $[1 \%(\mathrm{v} / \mathrm{v})$ Triton X-100, $50 \mathrm{mM}$ Tris- $\mathrm{HCl}, 5 \mathrm{mM} \mathrm{CaCL} 2$, and $1 \mu \mathrm{m} \mathrm{ZnCl} 2$ in $\mathrm{dH}_{2} \mathrm{O}$ with $0.02 \%(\mathrm{w} / \mathrm{v}) \mathrm{NaN}_{3}$ ] for $24 \mathrm{~h}$ at $37^{\circ} \mathrm{C}$, were stained with $0.2 \%$ (w/v) amido black (Thermo Fisher Scientific) and de-stained with $30 \%$ (v/v) acetic acid. Densitometric analysis of gels was performed in ImageJ v.1.6 $(\mathrm{NIH})$ and relative protease expression determined.

\section{Colorimetric Protease Detection}

The Azocasein method (Andrejko et al., 2013) was utilized to demonstrate total extracellular protease production. Here, $100 \mu \mathrm{l}$ SN was added to $100 \mu \mathrm{l}$ of Azocasein (Sigma-Aldrich) solution $\left(5 \mathrm{mg} / \mathrm{ml}\right.$ in $0.1 \mathrm{M}$ Tris-HCL, $\mathrm{pH} 8.8$ ) and incubated at $37^{\circ} \mathrm{C}$ for $3 \mathrm{~h}$. The reaction was stopped with $10 \%(\mathrm{v} / \mathrm{v})$ trichloroacetic acid (25 $\mu \mathrm{l}$ per tube) and samples were centrifuged at $14,000 \times g$ for $15 \mathrm{~min}$ at RT. To each well of a 96 -well plate, $50 \mu \mathrm{l}$ of $0.5 \mathrm{M} \mathrm{NaOH}$ was added to $50 \mu \mathrm{l}$ of Azocasein $\mathrm{SN}$ in triplicate. $\mathrm{NaOH}$ was used as a blank, bacterial protease (Sigma-Aldrich) was included as a positive control, and absorbance was measured at $405 \mathrm{~nm}$. For the Azocasein assay, one protease activity unit was defined as an absorbance increase $\left(\mathrm{OD}_{405} \mathrm{~nm}\right)$ of 0.02 per hour (Andrejko et al., 2013).

\section{Virulence Factor Gene Expression}

Samples snap frozen in liquid nitrogen were cut into $<1 \mathrm{~mm}$ pieces, added to $1 \mathrm{ml}$ Invitrogen ${ }^{\mathrm{TM}}$ RNAlater $^{\mathrm{TM}}$ Stabilization Solution (Thermo Fisher Scientific) and $5 \mathrm{ml}$ sterile borosilicate glass beads. Biofilm aggregates were dissociated from porcine skin as above and $\mathrm{SN}$ was centrifuged at $4^{\circ} \mathrm{C}$ to pellet bacterial cells. $P$. aeruginosa cell pellets were re-suspended in Max Bacterial Enhancement Reagent (Thermo Fisher Scientific) following the manufacturer's protocol. RNA was then isolated with TRIzol ${ }^{\circledR}$ reagent (Invitrogen, Thermo Fisher Scientific) and the aqueous phase purified with the PureLink RNA Mini Kit (Invitrogen, Thermo Fisher Scientific) following manufacturer's instructions. RNA quantity was assessed using a Nanodrop spectrophotometer (Thermo Fisher Scientific), and reverse transcribed with Bioscript (Bioline). cDNA samples were diluted by three orders of magnitude and RT-qPCRs were carried out with Takyon mastermix (Eurogentec) on an IQ5 thermocycler (Bio-Rad Laboratories Ltd.). Relative expression was normalized using the housekeeping genes $16 S$ and $r p o D$. Primer sequences were as follows: aprA: sense 5'-CTTCAATACGCCGTGGAAGT-3'; antisense 5'-GCGTCGACGAAGTGGATATT-3'; algD: sense 5' ATCAG CATCTTTGGTTTGGG-3' ${ }^{\prime}$; antisense $5^{\prime}$-CACCAATG ACTTCATGACCG-3'; lasB: sense 5'-GTCGCAGTACTACAAC GGCA-3' ; antisense $5^{\prime}$-ATTGGCCAACAGGTAGAACG-3'; 16S: sense $5^{\prime}$-GTGGAAAAGAGCTTCTGGCA-3'; antisense $5^{\prime}$-CTT CTCGACGATGATTTCCG-3'; and rpoD: sense $5^{\prime}$-GCGACG GTATTCGAACTTGT-3' ${ }^{\prime}$; antisense 5' ${ }^{\prime}$-CGAAGAAGGAAATGG TCGAG-3'.

\section{Host-Response \\ Masson's Trichrome Staining}

Porcine skin and wounds were created for assessment of tissue culture viability. Skin and wounds were prepared as above and samples were cultured in DMEM containing $10 \%(\mathrm{v} / \mathrm{v}) \mathrm{FBS}$, at $37^{\circ} \mathrm{C}$ and $5 \% \mathrm{CO}_{2}$ for $48 \mathrm{~h}$. Explants were then bisected at their midpoint and (a) embedded in OCT or (b) fixed in $4 \%(\mathrm{v} / \mathrm{v})$ saline-buffered formalin, processed, and embedded in paraffin wax. Overall structural assessment was performed with a modified version of the Goldner (1938) Masson's trichrome stain. Sections brought to $\mathrm{dH}_{2} \mathrm{O}$ were stained in Weigert's hematoxylin and Biebrich-Scarlet fuchsin, differentiated in phosphotungsticphosphomolybdic acid and counterstained with Aniline Blue 
(all reagents from Sigma-Aldrich). Sections were dehydrated in $100 \%$ ethanol and mounted in Pertex ${ }^{\circledR}$ (CellPath). Brightfield images were taken as above.

\section{Immunohistochemistry}

OCT embedded biofilm wounds, sectioned at $10 \mu \mathrm{m}$, were blocked in appropriate serum and incubated in primary antibodies $\mathrm{O} / \mathrm{N}$ at $4^{\circ} \mathrm{C}$. The antibodies used were the early apoptosis marker, goat anti-caspase 3 (R\&D Systems), and the cell-proliferation marker, mouse anti-Ki67 (Novocastra). Alexa Fluor conjugated secondary antibodies (Thermo Fisher Scientific) were used to detect antibody binding. Sections were counterstained in DAPI and mounted in Mowiol 4-88 with DABCO (Thermo Fisher Scientific). Fluorescent images were taken as above using the DAPI, FITC and TEXAS RED filters.

\section{Terminal Deoxynucleotidyl Transferase dUTP Nick End Labeling}

An In Situ Cell Death Detection Kit (Roche) was used for "TUNEL" staining according to manufacturer's instructions, using Proteinase K (Thermo Fisher Scientific) antigen retrieval prior to enzyme incubation. Fluorescent images were taken as above.

\section{Picrosirius Red Staining}

OCT sections were stained with Picrosirius Red to assess host matrix damage. Here, red birefringence indicated the presence of type I collagen, while yellow-green birefringence demonstrated the presence of type III collagen (Junqueira et al., 1979). Methanol-fixed sections were incubated in Picrosirius Red solution ( $0.5 \mathrm{~g}$ Sirius Red in $500 \mathrm{ml}$ saturated picric acid, Sigma-Aldrich) for $1 \mathrm{~h}$ at RT, differentiated in $0.5 \%(\mathrm{v} / \mathrm{v})$ acetic acid, dehydrated in ethanol, cleared in xylene and mounted in Pertex ${ }^{\circledR}$ (CellPath). Polarized light images were taken on a Nikon E400 microscope with SPOT camera (SPOT imaging) using a polarizing filter set (Thermo Fisher Scientific). Analysis of collagen fiber composition was performed in ImageJ v.1.6 (NIH).

\section{Statistical Analyses}

Data are expressed as average values \pm standard deviations of the mean. $P$-values of less than 0.05 were considered significant. All statistical tests were performed in R v.3.3.3 (R Development Core Team, 2017) including the car (Fox and Weisberg, 2011) package. $T$-tests and one-way ANOVAs were completed, followed by Tukey's HSD (honest significant differences) post hoc tests where applicable.

\section{RESULTS}

\section{Silver Bioactive Glass $\left(\mathrm{Bg}^{\mathrm{Ag}}\right)$ Elicited Potent Antimicrobial Efficacy Against Planktonic Cultures of $P$. aeruginosa and \\ S. aureus}

Agar diffusion assays with planktonic bacteria revealed differential effects for non-silver functionalized bioactive glass
$(\mathrm{Bg})$ and $\mathrm{AgO}$-functionalized bioactive glass $\left(\mathrm{Bg}^{\mathrm{Ag}}\right)$ against $P$. aeruginosa and $S$. aureus (Figures 1A-D). Interestingly, Bg, which was moderately effective at inhibiting $P$. aeruginosa growth, displayed no inhibitory effect on $S$. aureus. By contrast, $\mathrm{Bg}^{\mathrm{Ag}}$ elicited potent antimicrobial efficacy against both $P$. aeruginosa and $S$. aureus following 24- or 48-h treatments. The silver treatment alone (Ag), at equimolar concentration to the silver oxide component of $\mathrm{Bg}^{\mathrm{Ag}}$, exhibited only marginal (non-significant) antimicrobial efficacy. Next, time-kill assays were used to define the temporal antimicrobial efficacy of $\mathrm{Bg}, \mathrm{Bg}^{\mathrm{Ag}}$, and $\mathrm{Ag}$. In this assay, all treatments were potently antimicrobial (statistically significant 6-log reduction within $2 \mathrm{~h}$ ). However, interesting species- and treatment-specific differences were observed. Both $\mathrm{Bg}$ and $\mathrm{Bg}^{\mathrm{Ag}}$ led to a 6-log reduction in $P$. aeruginosa within $30 \mathrm{~min}$, whereas this level of reduction took $60 \mathrm{~min}$ for Ag treatment (Figure 1E). S. aureus experiments revealed even greater differential treatment effects. Here, $\mathrm{Bg}^{\mathrm{Ag}}$
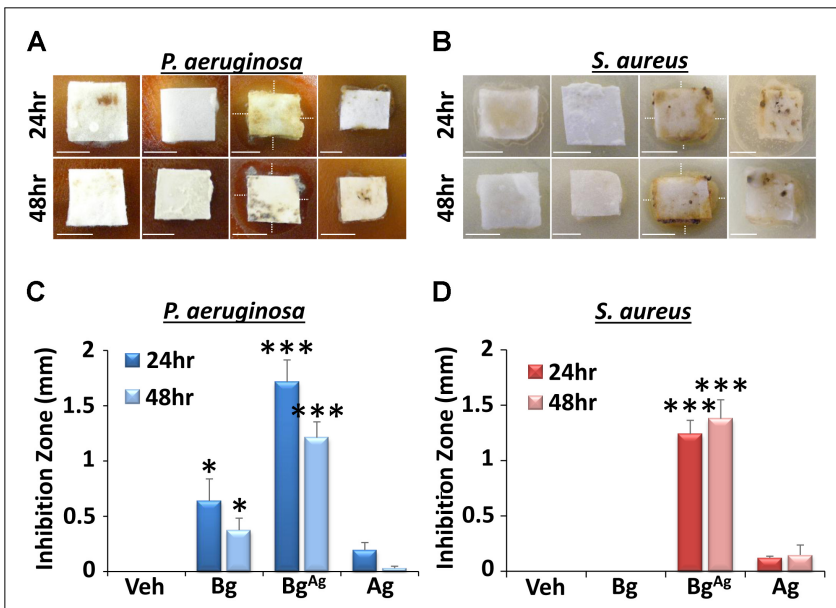

E

F
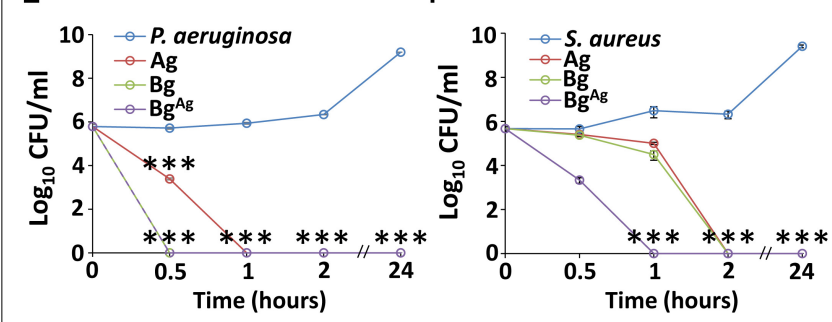

FIGURE 1 | Planktonic agar diffusion (A-D) and time-kill (E,F) assays reveal differential antimicrobial effects of bioactive glass against $P$. aeruginosa $(\mathbf{A}, \mathbf{C}, \mathbf{E})$ and S. aureus (B,D,F). Inhibition zones (depicted by white, dotted lines) of agar diffusion assays were significantly greater in the Bg incorporating silver $\left(\mathrm{Bg}{ }^{\mathrm{Ag}}\right)$ group compared to treatment with $\mathrm{Bg}$ alone $(\mathrm{Bg})$, or a silver control (Ag). This effect was observed at both 24 and $48 \mathrm{~h}$ post-treatment, against $P$. aeruginosa $(\mathbf{A}, \mathbf{C})$ and $S$. aureus $(\mathbf{B}, \mathbf{D})$, respectively. Interestingly, $\mathrm{Bg}$ significantly inhibited $P$. aeruginosa growth, but had no effect against S. aureus at both 24 and $48 \mathrm{~h}$. As expected, the vehicle (Veh) created no inhibition zones against $P$. aeruginosa or $S$. aureus. Time-kill assays further illustrated disparate effects of $\mathrm{Bg}$ and $\mathrm{Bg}{ }^{\mathrm{Ag}}$ against $P$. aeruginosa and S. aureus. Here, $\mathrm{Bg}^{\mathrm{Ag}}$ caused a 6-log reduction in $P$. aeruginosa (E) and $S$. aureus $(\mathbf{F})$ within $30 \mathrm{~min}$ and $1 \mathrm{~h}$, respectively. Data show the mean \pm SEM. ${ }^{*} P<0.05$ and ${ }^{* * *} P<0.001$. Scale bars $=5 \mathrm{~mm}$. Data were obtained from three independent experiments ( $n=3$ per treatment). 
alone led to a 6-log reduction in $S$. aureus within $1 \mathrm{~h}$, while $\mathrm{Bg}$ and $\mathrm{Ag}$ took $2 \mathrm{~h}$ to achieve similar antimicrobial efficacy (Figure 1F). In summary, both agar diffusion and time-kill assays revealed both $\mathrm{Bg}$ and $\mathrm{Bg}^{\mathrm{Ag}}$ to be potently antimicrobial against $P$. aeruginosa, while $\mathrm{Bg}^{\mathrm{Ag}}$ maintained greater antimicrobial efficacy against $S$. aureus than $\mathrm{Bg}$ or Ag alone.

\section{$\mathrm{Bg}{ }^{\mathrm{Ag}}$, but Not Bg, Displays Maintained Antimicrobial Efficacy Over a Clinically Meaningful Time Frame}

Agar diffusion assays were conducted using treatments that had been incubated at $4^{\circ} \mathrm{C}$ or $\mathrm{RT}$ for $24-120 \mathrm{~h}$ prior to assay
(Figure 2). When newly constituted $\mathrm{Bg}^{\mathrm{Ag}}$ and $\mathrm{Ag}$ were preincubated at $4^{\circ} \mathrm{C}$, significant efficacy against $P$. aeruginosa was maintained over a period of $120 \mathrm{~h}$. Bg on the other hand, maintained efficacy for only $72 \mathrm{~h}$ at $4^{\circ} \mathrm{C}$ (Figure 2A). Switching to $\mathrm{RT}$, both $\mathrm{Bg}^{\mathrm{Ag}}$ and $\mathrm{Ag}$ maintained potent efficacy against $P$. aer over a period of $120 \mathrm{~h}$. By contrast, Bg displayed little inhibition at any time point (Figure 2B). In keeping with previous agar diffusion results (Figure 1), no $S$. aureus growth inhibition was observed following treatment with pre-incubated $\mathrm{Bg}$ at $4^{\circ} \mathrm{C}$ or RT (Figures 2C,D). By contrast $\mathrm{Bg}^{\mathrm{Ag}}$ and $\mathrm{Ag}$ maintained efficacy against $S$. aureus over $120 \mathrm{~h}$ at both $4^{\circ} \mathrm{C}$ and RT (Figures 2C,D). An alternative measure related to treatment efficacy is the capacity to release antimicrobial over time. Here,
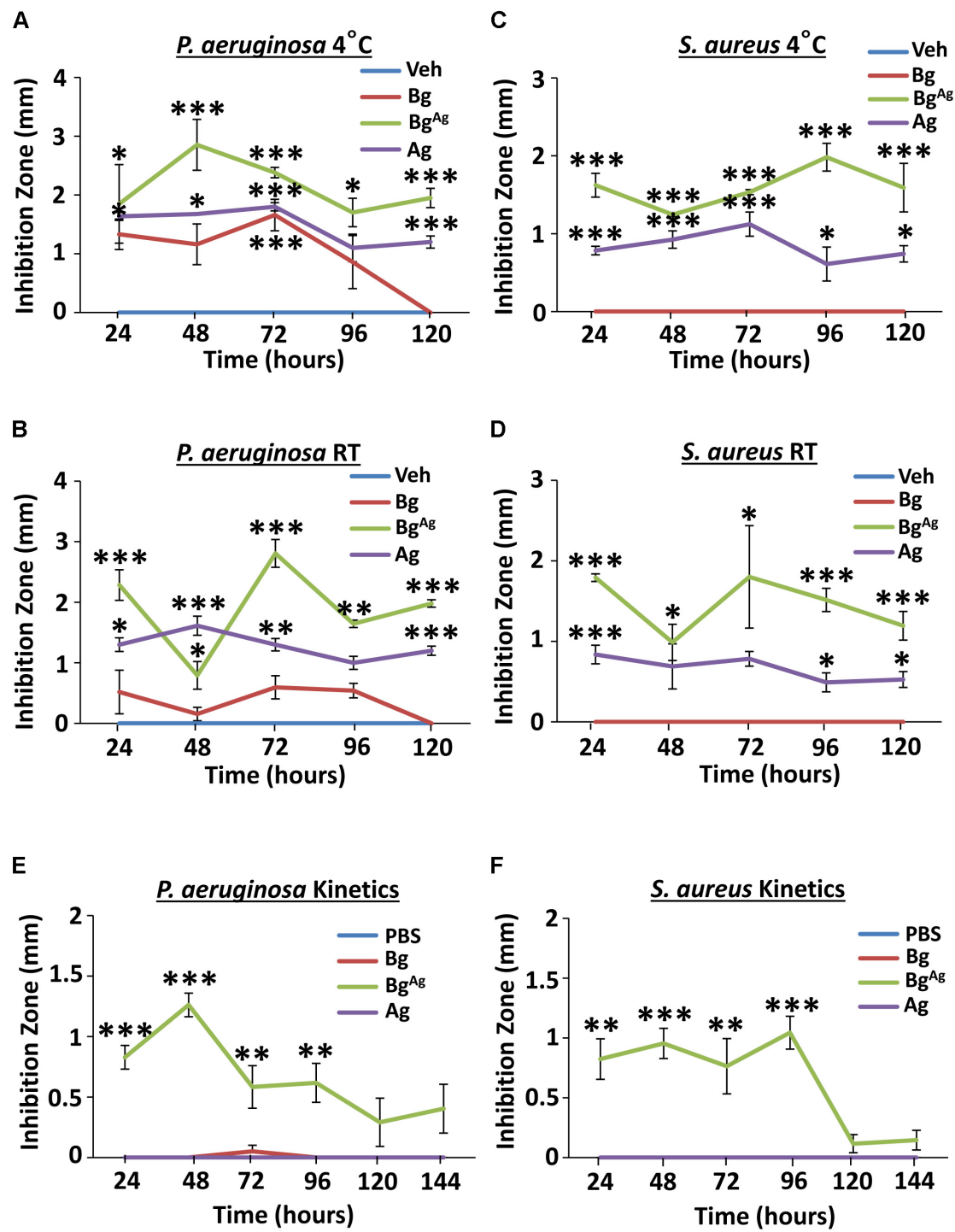

FIGURE 2 | Bioactive glass incorporating silver maintains stability and releases soluble antimicrobial factors over a clinically relevant time frame. Bg, Ag, and BgAg, pre-incubated at $4^{\circ} \mathrm{C}(\mathbf{A})$ and $\mathrm{RT}$ (B) prior to 24-h agar diffusion assays, showed differential antimicrobial efficacy against $P$. aeruginosa. BgAg and Ag caused significant S. aureus growth inhibition at $4^{\circ} \mathrm{C}$ (C) and RT (D). Kinetic testing revealed release of soluble antimicrobial factors from Bg ${ }^{A g}$, with potent antimicrobial effectiveness against $P$. aeruginosa (E) and S. aureus (F). Points show the mean \pm SEM. $* P<0.05$, ${ }^{* *} P<0.01$, and ${ }^{* * *} P<0.001$. Data were obtained from three independent experiments ( $n=3$ per treatment). 
the kinetics of release was measured by serial incubation of $\mathrm{Bg}$, $\mathrm{Ag}$, or $\mathrm{Bg}^{\mathrm{Ag}}$ in PBS over six consecutive periods of $24 \mathrm{~h}$. Here, $\mathrm{Bg}$ and $\mathrm{Ag}$ showed no antimicrobial efficacy against $P$. aeruginosa or $S$. aureus at any time point (Figures $2 \mathbf{E}, \mathbf{F}$ ). $\mathrm{Bg}^{\mathrm{Ag}}$, however, strongly inhibited the growth of $P$. aeruginosa and $S$. aureus for up to $96 \mathrm{~h}$ (Figures 2E,F). Collectively, these data show that both $\mathrm{Ag}$ and $\mathrm{Bg}^{\mathrm{Ag}}$ are highly stable, while $\mathrm{Bg}^{\mathrm{Ag}}$ alone is able to release soluble antimicrobial factors over a 4-day time frame.

\section{Biofilm Formation Was Impaired by BG Treatment, With Differential Effectiveness Against $P$. aeruginosa, $S$. aureus, and Co-cultured Bacteria}

Given the potent effects of $\mathrm{Bg}$ and $\mathrm{Bg}^{\mathrm{Ag}}$ against planktonic bacteria, we next asked whether $\mathrm{Bg}$ or $\mathrm{Bg}^{\mathrm{Ag}}$ were able to inhibit the formation of biofilms (microtiter method at $\mathrm{OD}_{495 \mathrm{~nm}}$; Table 1). In the absence of treatment, $P$. aeruginosa was considerably more effective at forming biofilm than $S$. aureus, or co-cultured bacteria (Table 2), which reflects previous studies (Bose et al., 2012; Nguyen and Oglesby-Sherrouse, 2016). S. aureus biofilm formation was entirely inhibited by $0.625 \%$ $\mathrm{Bg}^{\mathrm{Ag}}$, while $\mathrm{Bg}$ treatment at the same concentration had no effect on S. aureus biofilm formation. For P. aeruginosa, both $\mathrm{Bg}$ and $\mathrm{Bg}^{\mathrm{Ag}}$ strongly inhibited biofilm formation at higher concentration (0.625\%). However, at the lower $0.15 \%$, only $\mathrm{Bg}^{\mathrm{Ag}}$ was able to partially inhibit biofilm formation. These results were recapitulated in co-culture, where $0.625 \% \mathrm{Bg}$ had little effect on biofilm formation, while $0.625 \% \mathrm{Bg}^{\mathrm{Ag}}$ strongly inhibited biofilm formation. Taken together these data reveal greater anti-biofilm efficacy for $\mathrm{Bg}^{\mathrm{Ag}}$ than $\mathrm{Bg}$ alone.

\section{$\mathrm{Bg}^{\mathrm{Ag}}$ Reduces Both $P$. aeruginosa and S. aureus Biofilms in an ex Vivo Porcine Wound Model}

To more faithfully replicate the in vivo environment, we turned to a combined ex vivo porcine skin/established bacterial biofilm model. Here, viable porcine wound explants were cultured following apical surface inoculation with established $P$. aeruginosa or $S$. aureus biofilms (Figure 3). Treatment for $24 \mathrm{~h}$ with $\mathrm{Bg}, \mathrm{Bg}^{\mathrm{Ag}}$, or $\mathrm{Ag}$ alone led to a visible reduction in biofilm thickness. Representative images illustrate biofilms visualized using Gram-Twort ( $P$. aeruginosa, pink; $S$. aureus, purple; Figures 3A,D), ConA (Figures 3B,E), and AO
(Figures 3C,F). Quantification of biofilm thickness from GramTwort stained sections across multiple replicates revealed that $\mathrm{Bg}^{\mathrm{Ag}}$ treatment alone led to a statistically significant reduction in biofilm thickness (Figures 3G,H). Post-treatment viable colony enumeration $(\mathrm{CFU} / \mathrm{ml})$ was performed in parallel on dissociated biofilms. Here, all three treatments significantly reduced the number of viable biofilm bacteria ( $P$. aeruginosa and $S$. aureus biofilms; Figures $\mathbf{3} \mathbf{I}, \mathbf{J}$ ), with $\mathrm{Bg}^{\mathrm{Ag}}$ showing greatest efficacy against both bacterial species. These data directly demonstrate that silver-functionalized bioactive glass is effective against established ex vivo biofilms.

\section{$\mathrm{Bg}, \mathrm{Bg} \mathrm{Ag}$, and $\mathrm{Ag}$ Treatments Differentially Influence $P$. aeruginosa Biofilm Virulence Factor Production}

Bacterial colony enumeration alone does not directly convey bacterial pathogenicity (reviewed in Kallstrom, 2014), and effective invasion and adherence are fundamental requirements for establishing wound tissue infection (reviewed in Percival and McCarty, 2015). Thus, biofilm virulence was investigated via quantitative evaluation of extracellular protease activity and analysis of candidate virulence gene expression. In P. aeruginosa, these virulence factors include the endoproteases elastase (LasB) and alkaline protease (AprA), and alginate (AlgD; Goodman and Lory, 2004; Chu et al., 2016).

Zymography was performed to elucidate changes in bacterial protease activity (Figure 4). $P$. aeruginosa biofilm samples gave a range of bands on a gelatin zymogram (original gel, Supplementary Figure S1). Quantification was performed for the principle bands $(\sim 70$ and $\sim 50 \mathrm{kDa})$ in addition to total activity. Protease activity depicted by band $1(\sim 70 \mathrm{kDa})$, described as a distinct version of elastase (Lomholt et al., 2001), was significantly inhibited by $\mathrm{Bg}^{\mathrm{Ag}}$ compared to the vehicle (Figures $4 \mathbf{A}, \mathbf{B}$ ), but not $\mathrm{Bg}$ or $\mathrm{Ag}$ alone. A different pattern of activity, where both $\mathrm{Bg}$ and $\mathrm{Bg}^{\mathrm{Ag}}$ reduced expression compared to the vehicle control, was observed for band $2(\sim 50 \mathrm{kDa})$, which corresponds to the molecular mass of alkaline protease activity (Caballero et al., 2001; Lomholt et al., 2001; Figures 4A,C). Finally, when total protease activity within each lane was measured, $\mathrm{Bg}^{\mathrm{Ag}}$ and $\mathrm{Bg}$ significantly inhibited protease activity (Figures 4A,D). Independent colorimetric protease analysis, using the Azocasein method (Andrejko et al., 2013) was performed to quantify total biofilm protease activity following treatment (Figure 4E). Here, total protease activity was significantly reduced following $\mathrm{Bg}^{\mathrm{Ag}}$ treatment alone, compared to the vehicle.

TABLE 2 | The effects of bioactive glass $(\mathrm{Bg})$ and $\mathrm{Bg}$ with silver $\left(\mathrm{Bg}^{\mathrm{Ag}}\right)$ on single-species and co-culture biofilm formation, based on OD measurements at $495 \mathrm{~nm}$.

\begin{tabular}{|c|c|c|c|c|c|c|c|c|c|}
\hline Treatment & \multicolumn{3}{|c|}{ S. aureus NCTC 13297} & \multicolumn{3}{|c|}{ P. aeruginosa NCTC 10781} & \multicolumn{3}{|c|}{ Co-culture } \\
\hline Bacteria & & 0.1 & Moderate & & 0.54 & Strong & & 0.14 & Moderate \\
\hline \multirow[t]{2}{*}{$\mathrm{Bg} \mathrm{Ag}$} & $0.625 \%$ & 0.04 & Non-adherent & $0.625 \%$ & 0.08 & Weak & $0.625 \%$ & 0.06 & Weak \\
\hline & $0.15 \%$ & 0.1 & Moderate & $0.15 \%$ & 0.23 & Strong & $0.15 \%$ & 0.09 & Moderate \\
\hline $\mathrm{Bg}$ & $0.625 \%$ & 0.11 & Moderate & $0.625 \%$ & 0.07 & Weak & $0.625 \%$ & 0.09 & Moderate \\
\hline
\end{tabular}




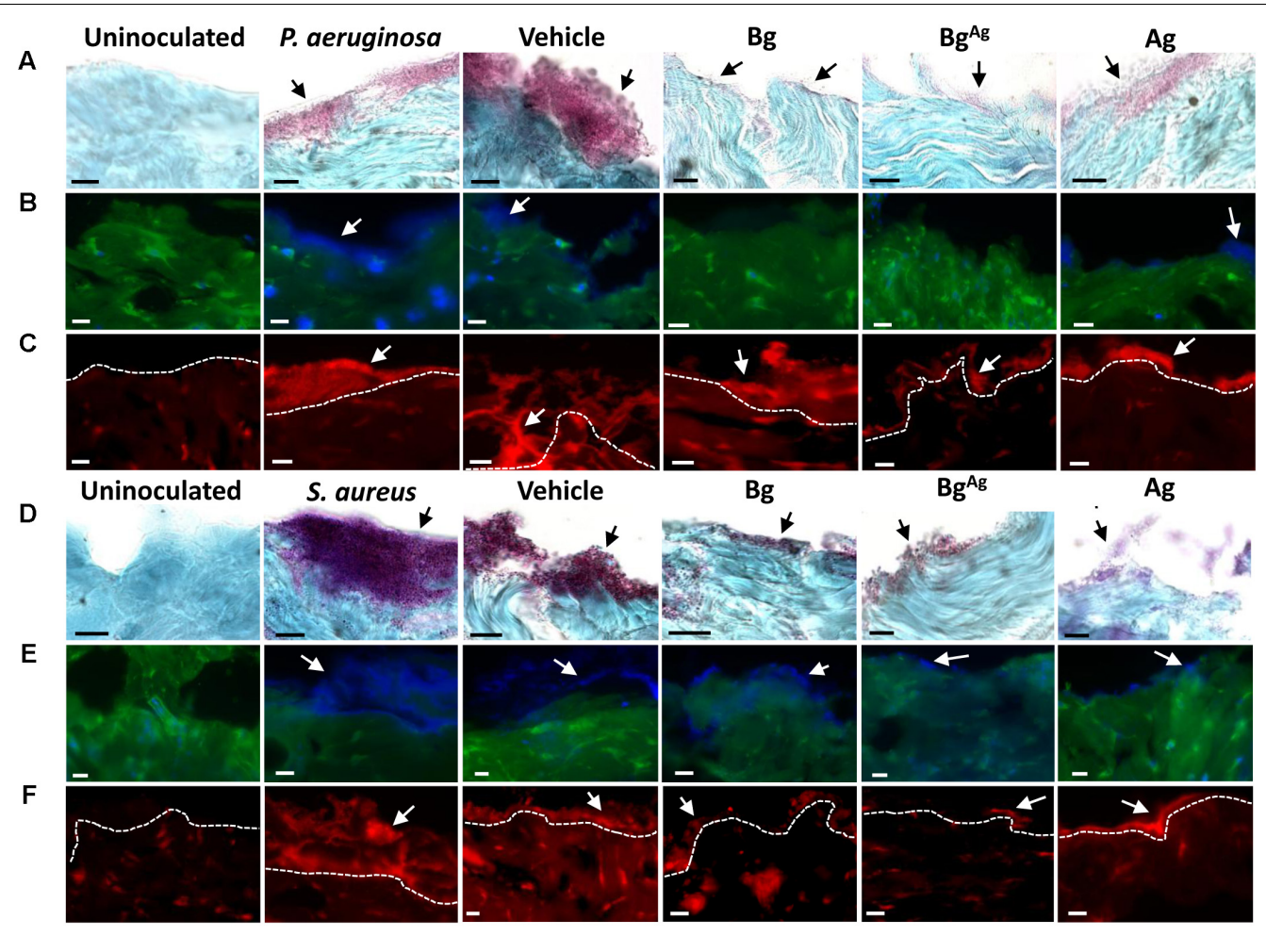

G

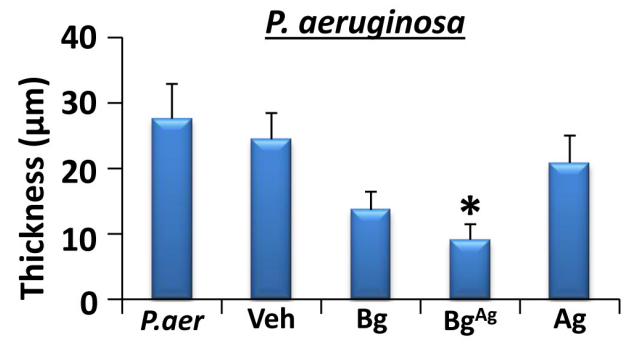

I

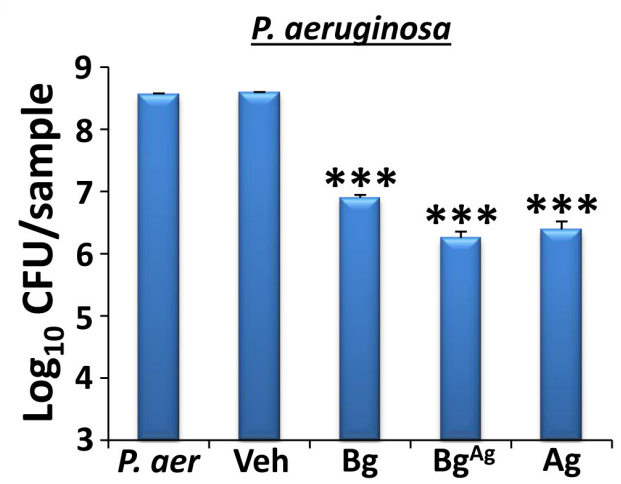

$\mathrm{H}$

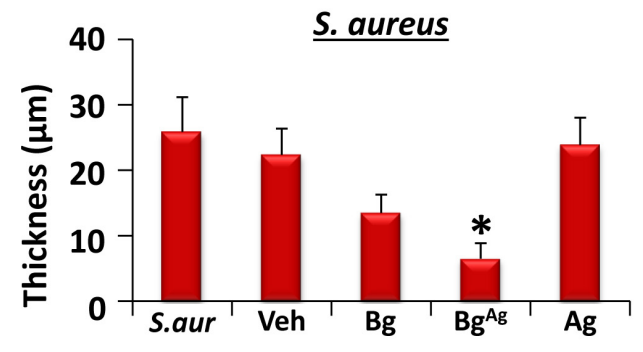

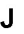

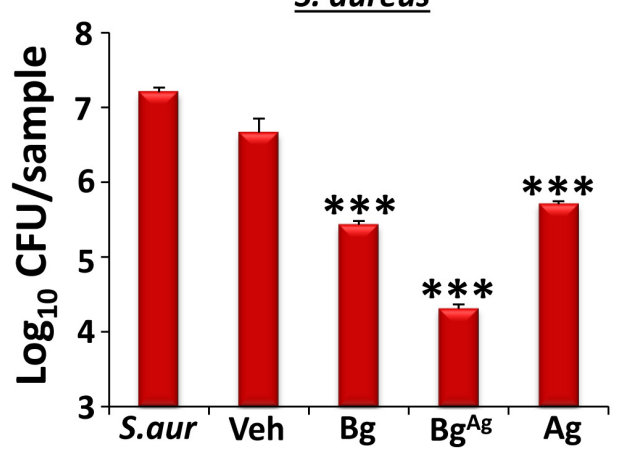

FIGURE 3 | Bioactive glass reduces biofilm load and bacterial viability in an ex vivo porcine wound biofilm model. Modified Gram-Twort staining illustrated a reduction in P. aeruginosa (P. aer; pink; A) and S. aureus (S. aur; purple; D) biofilm load (black arrows), on porcine skin (blue) following Bg, Bg Ag and Ag treatment. Quantification of Gram-Twort biofilm thickness ( $n=9$ images per treatment) showed a significant reduction in P. aeruginosa (G) and S. aureus (H) following BgAg treatment only. Similarly, Concanavalin A (blue biofilm, B,E) and Acridine Orange (red biofilm, C,F) staining demonstrated decreased $P$. aeruginosa (B,C) and S. aureus (E,F) biofilm (depicted by white arrows) following bioactive glass treatment. Biofilm was not apparent on uninoculated porcine wounds. Bg, $\mathrm{Bg}{ }^{\mathrm{Ag}}$ and $\mathrm{Ag}$ also significantly reduced $P$. aeruginosa $\mathbf{( I )}$ and S. aureus $\mathbf{( J )}$ porcine biofilm load (CFU/ml) within $24 \mathrm{~h}$ of treatment $(n=3$ biopsies per treatment). Black scale bars $=10 \mu \mathrm{m}$, white scale bars $=20 \mu \mathrm{m}$. Bars show mean \pm SEM. $* P<0.05$ and ${ }^{* * *} P<0.001$. 

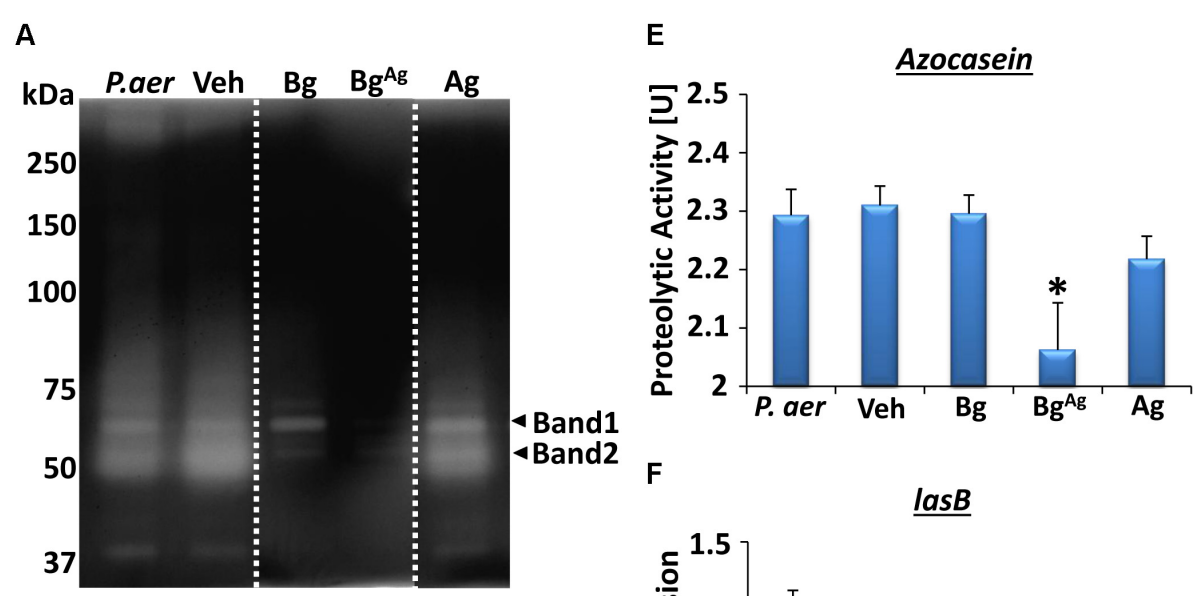

B
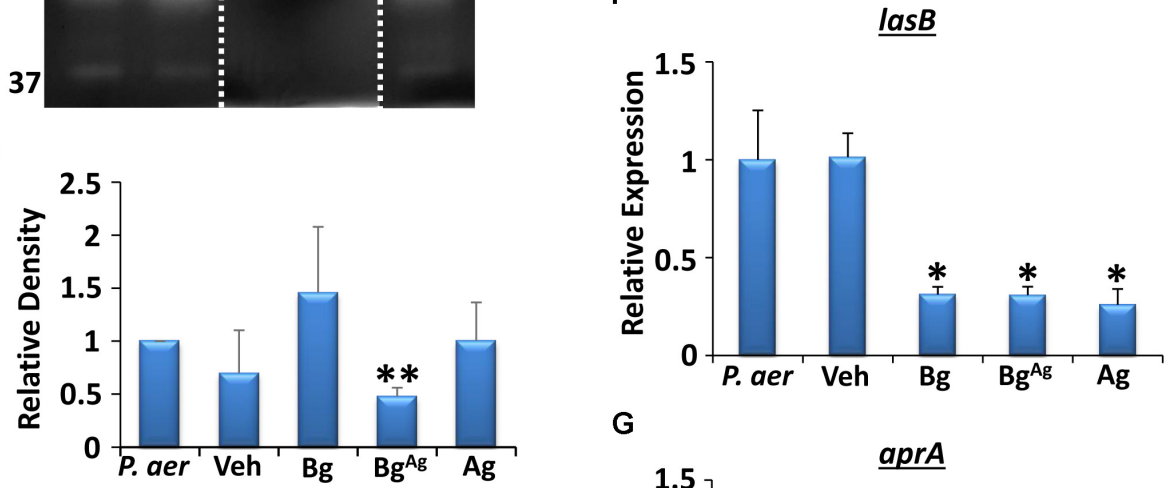

G

C

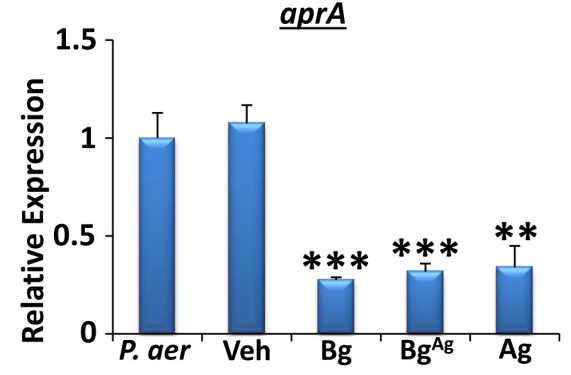

H
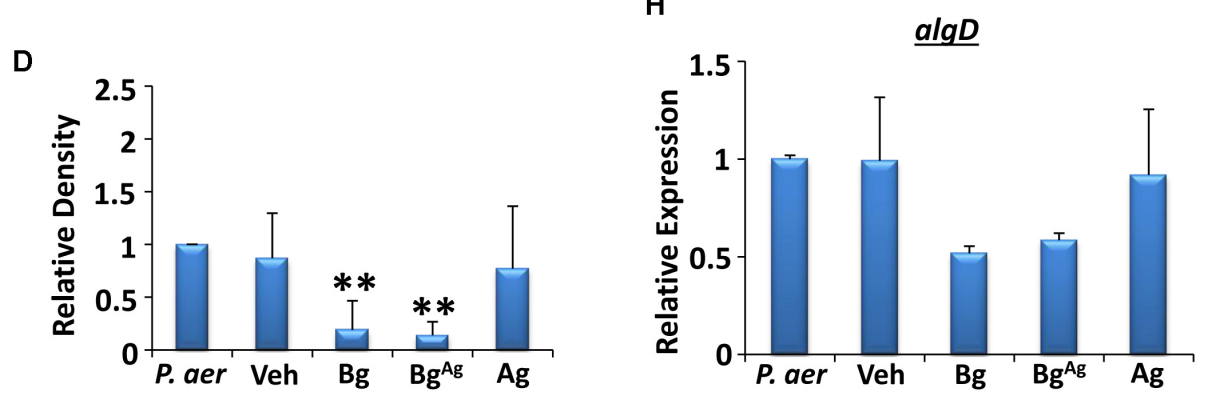

FIGURE 4 | Extracellular protease activity from $P$. aeruginosa ( $P$. aer) biofilms is differentially altered by bioactive glass treatment. Zymography analysis (A-D) illustrated changes in protease activity, where each lane showed $P$. aeruginosa biofilm ( $P$. aer), vehicle (Veh), Bg, BgAg, and Ag treatments, respectively (lanes were cut and placed in this order, as shown via a white dotted line, representative of three gels). Significantly dampened activity of the protease in band 1 ( $70 \mathrm{kDa}$; $\mathbf{A}, \mathbf{B})$ was shown following $\mathrm{Bg}^{\mathrm{Ag}}$ treatment, while both $\mathrm{Bg}$ and $\mathrm{Bg}^{\mathrm{Ag}}$ significantly reduced protease activity in band 2 ( $\left.\sim 50 \mathrm{kDa}, \mathbf{A}, \mathbf{C}\right)$, and overall protease action (D), compared to Veh. Colorimetric analysis (repeated in three independent experiments) of total extracellular protease (E) demonstrated a reduction in proteolytic activity with $\mathrm{Bg} A g$, compared to Veh. Significant reductions (compared to Veh) were also observed in expression of the virulence genes lasB (F) and aprA (G), while no significant changes were shown in algD $\mathbf{( H )}$, illustrated via RT-qPCR. Data represent the mean $\pm \mathrm{SEM}$. ${ }^{*} P<0.05, * * P<0.01$, and $* * * P<0.001$.

We next switched to evaluating virulence factor gene expression in $P$. aeruginosa biofilms. Analysis revealed that all three treatments significantly reduced expression of the gene lasB compared to Veh $(P<0.05$, Figure $4 \mathbf{F})$, important in encoding elastase B production (Casilag et al., 2016). Similarly,
Ag significantly reduced aprA expression $(P<0.01)$, a gene encoding alkaline protease (Lomholt et al., 2001; Figure 4G), while $\mathrm{Bg}$ and $\mathrm{Bg}^{\mathrm{Ag}}$ treatment led to a further reduction in aprA expression $(P<0.001)$. Finally, reduced expression of algD (important for alginate biosynthesis; Wiens et al., 2014) was 
apparent following $\mathrm{Bg}$ and $\mathrm{Bg}{ }^{\mathrm{Ag}}$ treatment, although this failed to reach significance (Figure $\mathbf{4 H}$ ).

\section{$\mathrm{Bg}^{\mathrm{Ag}}$ Protects Porcine Tissue From Biofilm Induced Dermal Cell Death and ECM Turnover}

We next switched our attention to assessing the direct effects of bacterial biofilm exposure on porcine wound tissue. Initial histological evaluation of non-biofilm infected skin revealed comparable levels of cell proliferation prior to culture (4\%) versus after $48 \mathrm{~h}$ of ex vivo culture (3\%; Figure 5D), agreeing with previously published data (Yeung et al., 2016). Similarly, only a marginal increase in cell death was observed following $48 \mathrm{~h}$ of ex vivo culture, with around $20 \%$ of cells TUNEL $^{+ \text {ve }}$ (Figures 5B,E) and around 5\% of cells undergoing apoptosis (caspase $3^{\text {ve }}$; Figures $5 \mathbf{C , F}$ ). In stark contrast, skin that was maintained ex vivo for $48 \mathrm{~h}$ in the presence of biofilm displayed significantly high levels of decellularity compared to pre-cultured tissue (Figures 5G,H). Notably, Bg
A
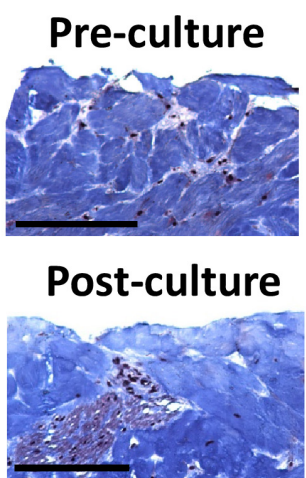

D

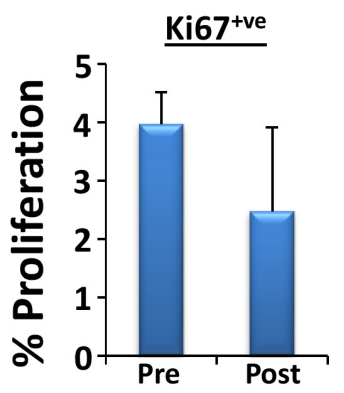

B

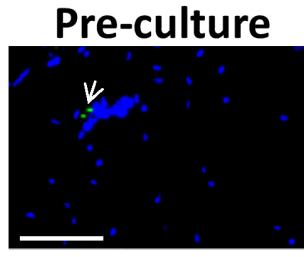

C

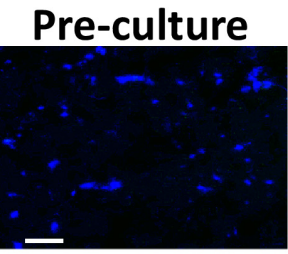

E

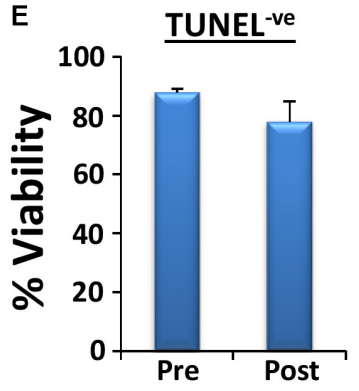



Post-culture

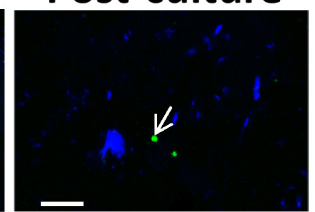

F $\quad$ Caspase $3^{\text {+ve }}$

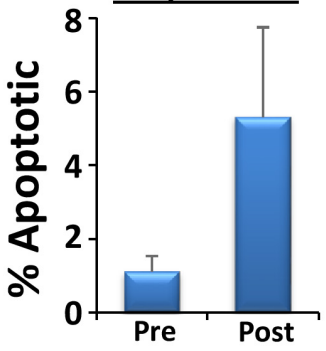

G

H

Cellularity
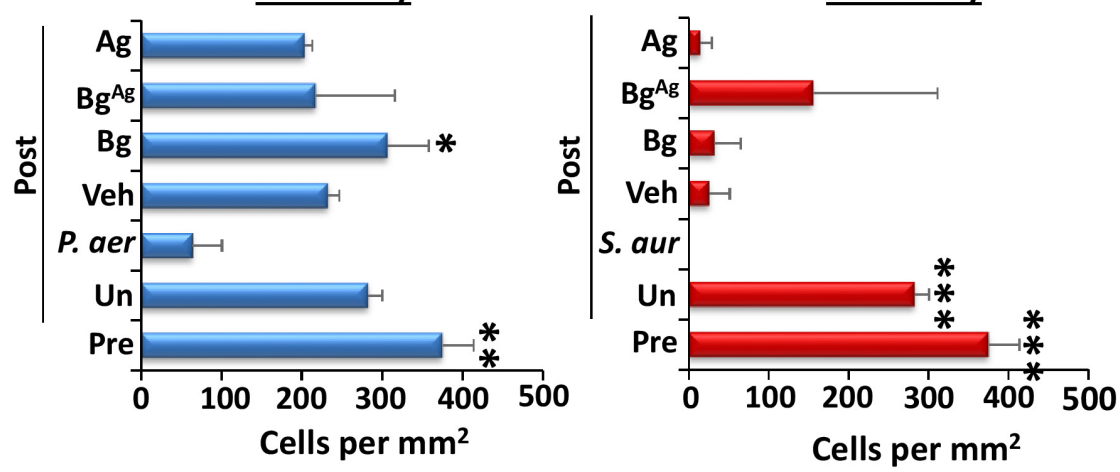

FIGURE 5 | Viability of porcine explants is drastically reduced by biofilm treatment, yet BgAg prevents decellularization. Viability of uninoculated porcine tissue over the 48 -h culture period was assessed via comparison of wounds pre-culture ("Pre") and post-culture ("Post") at $37^{\circ} \mathrm{C}$ and $5 \% \mathrm{CO} 2$ ( $n=3$ per group). Viability was deduced via visualization of structure (A, Masson's trichrome staining), cell proliferation (Ki67+ve staining, D), cell viability (TUNEL ${ }^{-v e}$ cells, blue, B and E) and apoptosis (caspase $3^{+v e}$ cells, green, $\mathbf{C}$ and $\mathbf{F}$ ). Cell death following $P$. aeruginosa $(P$. aer, $\mathbf{G})$ and $S$. aureus $(S$. aur, $\mathbf{H})$ biofilm loading was assessed by measuring cellularity (number of DAPI stained cells per $\mathrm{mm}^{2}$ ) post-culture (48 $\mathrm{h}, n=9$ images per group). Cellularity of pre-culture porcine tissue was also assessed. Arrows depict positively stained green cells. Black bars $=100 \mu \mathrm{m}$, white bars $=20 \mu \mathrm{m}$. White arrows depict green (apoptotic) cells. ${ }^{*} P<0.05, * * P<0.01, * * * P<0.001$. 
treatment significantly reduced this biofilm-induced cell lysis in $P$. aeruginosa inoculated wounds (Figure 5G), while $\mathrm{Bg}^{\mathrm{Ag}}$ retained increased cellularity compared to biofilm controls. Finally, given the effects of bioactive glass treatment on bacterial protease production (Figure 4), we asked whether changes in skin extracellular matrix composition would be evident. Interestingly, biofilm infection increased collagen turnover at the biofilm skin interface [visualized by an increase in new (green birefringence) fiber production; Figure 6]. Again, treatment with $\mathrm{Bg}, \mathrm{Bg}^{\mathrm{Ag}}$, and Ag decreased this turnover in wounds inoculated with $P$. aeruginosa biofilms, reducing the amount of new matrix produced (Figures 6A,C). Interestingly, in $S$. aureus wounds, $\mathrm{Bg}^{\mathrm{Ag}}$ treatment alone maintained a protective effect against collagen turnover (Figures 6B,C). Thus, Bg treatment is not only effective at killing biofilm bacteria, but it also demonstrably reduces the direct detrimental effects of bacteria on the host tissue.

\section{Disparate Anti-biofilm Effects of BG on $P$. aeruginosa: S. aureus Co-culture Porcine Wound Biofilms}

The prevalence of polymicrobial infections is a major clinical problem, which contributes to the intransigent nature of chronic wounds (Pastar et al., 2013; Fleming et al., 2017). To partially mimic this phenomenon, we established a coculture porcine wound biofilm model. Interestingly, all three treatments were less effective at killing bacteria in co-cultured biofilms than in single culture biofilms (Figure 3). These effects were confirmed by direct visualization of the co-culture biofilms, where $\mathrm{Bg}, \mathrm{Bg} \mathrm{Ag}$, and $\mathrm{Ag}$ treatment led to no more than a mild qualitative reduction in wound biofilm load via Gram-Twort (Figure 7B), ConA (Figure 7C), and $\mathrm{AO}$ staining (Figure 7D). Quantification of biofilm thickness revealed only a non-significant trend toward reduced biofilm thickness following treatments (Figure 7A). We did, however, observe a statistically significant reduction in total $\mathrm{CFU}$ following $\mathrm{Bg}$, $\mathrm{Bg}^{\mathrm{Ag}}$, and Ag treatment of co-cultured biofilms (Figure 7E). Overall, these data demonstrated a less pronounced effect of $\mathrm{Bg}$ and $\mathrm{Bg}^{\mathrm{Ag}}$ against co-culture biofilms than single-species biofilms.

More clinically significant was the effect of treatments on the relative proportion of $P$. aeruginosa and $S$. aureus in co-cultured biofilms (Figure 7F). At the time of collection ( $48 \mathrm{~h}$ post tissue inoculation), vehicle-treated biofilms were quantified as 55:45 $P$. aeruginosa to $S$. aureus relative proportions. Ag treatment led to a modest non-significant shift in these proportions to around 65:35. By contrast, Bg treatment led to a large, statistically significant shift to almost 90:10 $(P<0.05$, in both $P$. aeruginosa and $S$. aureus contribution). The greatest effect was observed following $\mathrm{Bg}^{\mathrm{Ag}}$ treatment, where virtually no $S$. aureus could be recovered $(P<0.01$, in $P$. aeruginosa and $S$. aureus). These data, which mirror the differential selectivity of BG treatment against single-species biofilms (Figure 3), reveal the extent to which a topical wound treatment can alter the dynamic equilibrium between two bacterial species.

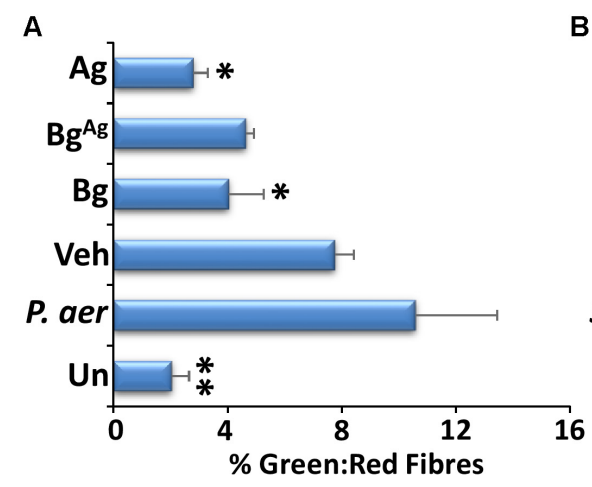

B

C
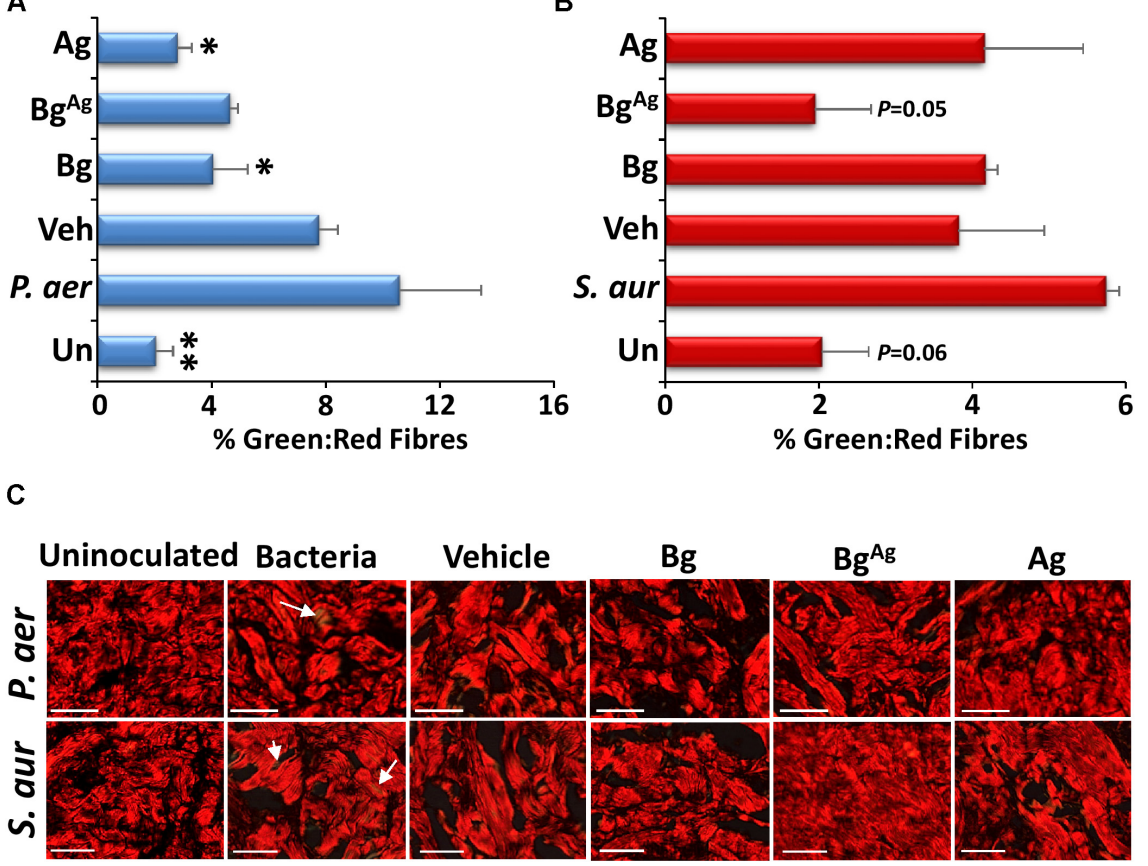

FIGURE 6 | Bioactive glass protects against extracellular matrix turnover. Picrosirius red staining of porcine biofilm tissue $(n=9$ per group) demonstrated changes in collagen III turnover via measurement of \% green: red fibers (green birefringence is demonstrated by white arrows). Significantly more collagen III turnover was demonstrated in P. aeruginosa (P. aer, A,C) biofilms compared to uninoculated controls, Bg and Ag treatments. S. aureus (S. aur, B,C) biofilms increased collagen III turnover compared to $\mathrm{Bg}^{\mathrm{Ag}}$ and uninoculated porcine explants. ${ }^{*} P<0.05,{ }^{* *} P<0.01$. White bars $=100 \mu \mathrm{m}$. 

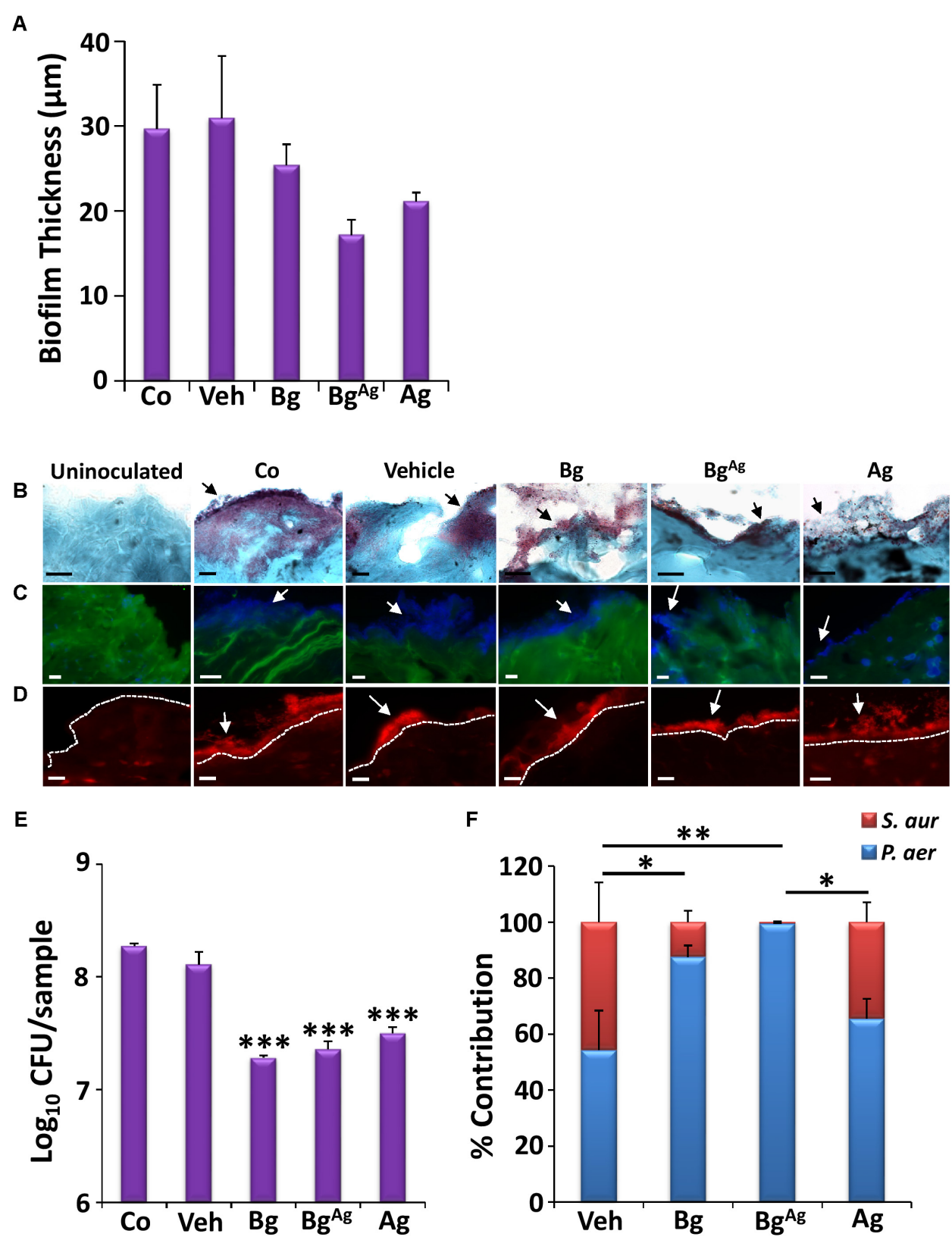

FIGURE 7 | Co-culture biofilms of $P$. aeruginosa (P. aer) and S. aureus (S. aur) appear more resistant to bioactive glass than single-species biofilms. Quantification of biofilm thickness (A; $n=9$ images per group) via Gram-Twort staining (B), revealed no significant change in biofilm load (black arrows) with bioactive glass treatment. Further visualization with Concanavalin A (C), blue biofilms), and Acridine Orange (D, red biofilms, above the white-dotted line) confirmed this, where white arrows illustrate biofilms. However, Bg, silver Bg (Bg $\left.{ }^{A g}\right)$, and silver alone (Ag) caused a significant reduction in porcine biofilm load (CFU/ml) within 24 h (E). The percentage of $P$. aeruginosa and $S$. aureus contributing to the co-culture porcine biofilms was also determined following treatment, where statistical analysis shows significant changes in the contribution of $P$. aeruginosa and $S$. aureus between treatments $(\mathbf{F})$. Black scale bars $=10 \mu \mathrm{m}$, white scale bars $=20 \mu \mathrm{m}$. Bars show the mean \pm SEM. ${ }^{*} P<0.05,{ }^{* *} P<0.01$, and $* * * P<0.001$.

\section{DISCUSSION}

Though it is axiomatic that silver has potent antimicrobial effects against a range of bacterial species (reviewed in Maillard and Hartemann, 2013), comparatively few studies have addressed the antimicrobial and anti-biofilm efficacy of BG formulations. Fewer still have explored BG formulations functionalized with silver (e.g., Drago et al., 2014; Gholipourmalekabadi et al., 2016). Here, we assessed the bactericidal activity of BG against planktonic and biofilm forms of wound-relevant bacteria ( $P$. aeruginosa and S. aureus; James et al., 2008). Our data clearly show that $\mathrm{BG}$ incorporating silver $\left(\mathrm{Bg}^{\mathrm{Ag}}\right)$ provided a more potent bactericidal effect against planktonic $P$. aeruginosa and $S$. aureus than $\mathrm{Bg}$ or $\mathrm{Ag}$ alone. Previously, Ag treatment has been 
shown to increase membrane permeability and potentiate the susceptibility of Gram-negative bacteria to antibiotics (MoronesRamirez et al., 2013). Therefore, in the present work, Ag may also be potentiating microbial susceptibility to bioactive glass. An important novel observation was the relative species-specific efficacy, with $\mathrm{Bg}$ more effective against planktonic $P$. aeruginosa than $S$. aureus (Figure 1). In agar diffusion tests, $\mathrm{Bg}$ alone failed to cause inhibition of $S$. aureus growth. One previously suggested reason for this is that bacterial metabolism (acid production) may circumvent increased $\mathrm{pH}$, thus reduce the diffusibility of $\mathrm{Bg}$ into agar (Stoor et al., 1998; Martins et al., 2011). However, the observed differential effects of Bg most likely reflect the differences in cell-wall structure between the two bacterial species. The Gram-positive $S$. aureus is encapsulated by a thickened peptidoglycan cell wall which has been suggested to convey increased resistance (Zoeiby et al., 2001). Indeed, a number of $S$. aureus strains maintain antibiotic-tolerance via cell wall-related mechanisms (Utaida et al., 2003; Dengler et al., 2011). The less substantial $P$. aeruginosa cell wall and membrane structure may confer susceptibility to the increased $\mathrm{pH}$ caused by $\mathrm{Bg}$ ion dissolution (e.g., $\left[\mathrm{Ca}^{2+}\right] \mathrm{i}$ and $\left[\mathrm{Na}^{+}\right] \mathrm{i}$ release; Stoor et al., 1998), thus altering bacterial membrane potential (Munukka et al., 2008) and causing osmotic stress (Van der Waal et al., 2011). Furthermore, regional variation in skin $\mathrm{pH}$ is thought to play a significant role in spatial localisation of skin bacteria (reviewed in Schreml et al., 2010), while S. aureus is known to favor more acidic conditions than $P$. aeruginosa (Ushijima et al., 1984). In the present study, the effects of BG may also be due to the antimicrobial efficacy of its relative components, e.g., $\mathrm{SiO}_{2}$ (Maçon et al., 2017; Siqueira et al., 2017).

Of more physiological relevance, BG significantly reduced $P$. aeruginosa and $S$. aureus biofilm load in an ex vivo porcine wound explant model, albeit less effectively than during in vitro planktonic assays (Figure 3). Curiously, species-specific efficacy was reversed in this biofilm model, with $S$. aureus more susceptible to BG treatment than $P$. aeruginosa. This may simply reflect the strong biofilm-producing ability of $P$. aeruginosa (Harrison-Balestra et al., 2003) accompanied by production of a multitude of extracellular proteases (Andrejko et al., 2013). By contrast, $S$. aureus forms weak biofilms initially, relying on adhesion proteins and autolysin production for its virulence and biofilm generation (Rice et al., 2007; Bose et al., 2012; Foulston et al., 2014). S. aureus favors acidic conditions in the clinical setting (Weinrick et al., 2004), and a well characterized drop in $\mathrm{pH}$ triggers $S$. aureus biofilm matrix production and subsequent cell aggregation. As $\mathrm{BG}$ treatment increases $\mathrm{pH}(\sim 10$ in the present study, data not shown), we postulate that alkaline stress caused by BG could contribute to reduced biofilm load. Here the literature is conflicting with respect to $S$. aureus; Foulston et al. (2014) report reduced biofilm formation at high $\mathrm{pH}$, while Van der Waal et al. (2011) report no effect on biofilm viability.

The most common method for determining bacterial load in samples is through assessing colony viability (Buysschaert et al., 2016). However, recent evidence suggests some bacteria, including $P$. aeruginosa and $S$. aureus, can enter a viable but not culturable (VBNC) state, where they may contribute to biofilm virulence (Zhang et al., 2015). Alterations in exogenous stimuli are known to modify $P$. aeruginosa virulence factor expression (Rumbaugh et al., 1999; Shigematsu et al., 2001; Breidenstein et al., 2011), largely through quorum-sensing systems (Dong and Zhang, 2005). In quantifying virulence factor expression, we focused on genes responsible for modulating protease production and bacterial cell-host matrix binding, fundamental requirements for establishing wound tissue infection (reviewed in Percival and McCarty, 2015). Bg, $\mathrm{Bg}^{\mathrm{Ag}}$, and $\mathrm{Ag}$ significantly reduced expression of the $P$. aeruginosa virulence factors; elastase (LasB) and alkaline protease (AprA; Goodman and Lory, 2004; Lee et al., 2013; Khosravi et al., 2016). Direct analysis of $P$. aeruginosa gelatinases confirmed the effect of bioactive glass, where $\mathrm{Bg}$ and $\mathrm{Bg}^{\mathrm{Ag}}$ demonstrated a substantial reduction in activity corresponding to elastase ( $\sim 37 \mathrm{kDa}$; Miyajima et al., 2001) and alkaline protease (50-75 kDa; Engel et al., 1997; Schmidtchen et al., 2003; Figure 4). Elastase (LasB) is particularly interesting as it exhibits potent widespread proteolytic activity, thus causing excessive wound tissue proteolysis (Kessler et al., 1998) while preventing normal dermal fibroblast growth (Schmidtchen et al., 2003). Indeed, when we assessed the effect of $P$. aeruginosa and $S$. aureus biofilms on host tissue we found reduced cellularity and increased matrix turnover (Figures 5, 6, respectively).

Chronic wounds are a term used to encompass all wounds that fail to heal within 12 weeks and can include, but are not limited to, diabetic foot ulcers, pressure sores, and venous leg ulcers (Rodriguez-Arguello et al., 2018). Chronic wounds often remain recalcitrant due to their diverse microbial communities (Gardner et al., 2013; Kalan et al., 2016), which can profoundly affect clinical outcome (Baldan et al., 2014; Wolcott et al., 2015). Although the consequences of interspecies interactions on wound pathogenesis remain to the elucidated, experimental studies have revealed that multiple-species biofilms exert major influence on host tissue responses, such as inflammation (Pastar et al., 2013). Therefore, we produced co-culture porcine biofilms of $S$. aureus and $P$. aeruginosa to further investigate the efficacy of BG treatment. Our experiments also revealed that cocultured biofilms were more resistant to BG treatment, where only a modest reduction in viability was observed (Figure 7). Experimentally producing polymicrobial biofilm communities can be difficult as one species often predominates (Malic et al., 2009; Dalton et al., 2011). In our study, untreated porcine biofilms adopted a stable ratio at around 60:40 P. aeruginosa to $S$. aureus, in line with the potentially synergistic relationship between the two species (Dalton et al., 2011; Korgaonkar et al., 2013; Pastar et al., 2013). Curiously, following BG-treatment, $P$. aeruginosa quickly became dominant. This supports studies demonstrating that $P$. aeruginosa may out-compete $S$. aureus when resources are limited, in part by sequestering vital cofactors, and producing metabolites toxic to S. aureus (Mashburn et al., 2005; Biswas et al., 2009; DeLeon et al., 2014).

Collectively, this study demonstrates clear potential for $\mathrm{Bg}$ and $\mathrm{Bg}^{\mathrm{Ag}}$ as potential wound-relevant antimicrobials. It is crucial that we continue to explore novel antimicrobial agents, especially for indications where mechanisms of antibiotic resistance and silver 
resistance are a concern (Su et al., 2011; Randall et al., 2015). This is particularly important when considering the polymicrobial interactions of clinical infections (Dalton et al., 2011). Although not addressed in the present study, BG presents an attractive opportunity for future functionalization with a variety of compounds designed to promote wound repair (Bonvallet et al., 2015; Wu et al., 2017). Combining this versatility with clear antimicrobial efficacy offers exciting opportunities for wound management.

\section{AUTHOR CONTRIBUTIONS}

HW and $\mathrm{MH}$ were involved in study design. HW and SI performed the experiments and analyzed the data. HW, SI, and $\mathrm{MH}$ interpreted the data. $\mathrm{HW}$ and $\mathrm{MH}$ wrote the manuscript. $\mathrm{HW}, \mathrm{SI}, \mathrm{PC}$, and $\mathrm{MH}$ read and approved the final manuscript for publication.

\section{REFERENCES}

Andrejko, M., Zdybicka-Barabas, A., Janczarek, M., and Cytryńska, M. (2013). Three Pseudomonas aeruginosa strains with different protease profiles. Acta Biochim. Pol. 60, 83-90.

Baldan, R., Cigana, C., Testa, F., Bianconi, I., De Simone, M., Pellin, D., et al. (2014). Adaptation of Pseudomonas aeruginosa in cystic fibrosis airways influences virulence of Staphylococcus aureus in vitro and murine models of co-infection. PLoS One 9:e89614. doi: 10.1371/journal.pone.0089614

Balouiri, M., Sadiki, M., and Ibnsouda, S. K. (2016). Methods for in vitro evaluating antimicrobial activity: a review. J. Pharm. Anal. 6, 71-79. doi: 10.1016/j.jpha. 2015.11.005

Bellantone, M., Coleman, N. J., and Hench, L. L. (2002). Silver-containing, sol/gel derived bioglass compositions. U.S. Patent No. 6,482,444. Washington, DC: U.S. Patent and Trademark Office.

Biswas, L., Biswas, R., Schlag, M., Bertram, R., and Götz, F. (2009). Small-colony variant selection as a survival strategy for Staphylococcus aureus in the presence of Pseudomonas aeruginosa. Appl. Environ. Microbiol. 75, 6910-6912. doi: 10. 1128/AEM.01211-09

Bjarnsholt, T., Kirketerp-Møller, K., Jensen, P. $\varnothing$, Madsen, K. G., Phipps, R., Krogfelt, K., et al. (2008). Why chronic wounds will not heal: a novel hypothesis. Wound Repair Regen. 16, 2-10. doi: 10.1111/j.1524-475X.2007.00283.x

Bonvallet, P. P., Schultz, M. J., Mitchell, E. H., Bain, J. L., Culpepper, B. K. Thomas, S. J., et al. (2015). Microporous dermal-mimetic electrospun scaffolds pre-seeded with fibroblasts promote tissue regeneration in full-thickness skin wounds. PLoS One 10:e0122359. doi: 10.1371/journal.pone.0122359

Bose, S., Roy, M., and Bandyopadhyay, A. (2012). Recent advances in bone tissue engineering scaffolds. Trends Biotechnol. 30, 546-554. doi: 10.1016/j.tibtech. 2012.07.005

Bowler, P. G. (2018). Antibiotic resistance and biofilm tolerance: a combined threat in the treatment of chronic infections. J. Wound Care 27, 273-277. doi: 10.12968/jowc.2018.27.5.273

Breidenstein, E. B., de la Fuente-Núñez, C., and Hancock, R. E. (2011). Pseudomonas aeruginosa: all roads lead to resistance. Trends Microbiol. 19, 419-426. doi: 10.1016/j.tim.2011.04.005

Buysschaert, B., Byloos, B., Leys, N., Van Houdt, R., and Boon, N. (2016). Reevaluating multicolor flow cytometry to assess microbial viability. Appl. Microbiol. Biotechnol. 100, 9037-9051.

Caballero, A. R., Moreau, J. M., Engel, L. S., Marquart, M. E., Hill, J. M., and O'Callaghan, R. J. (2001). Pseudomonas aeruginosa protease IV enzyme assays and comparison to other Pseudomonas proteases. Anal. Biochem. 290, 330-337.

Casilag, F., Lorenz, A., Krueger, J., Klawonn, F., Weiss, S., and Häussler, S. (2016). The LasB elastase of Pseudomonas aeruginosa acts in concert with

\section{FUNDING}

HW is supported by a Medical Research Council United Kingdom CASE Ph.D. studentship (grant number MR/M016307/1). SI is supported by a British Skin Foundation United Kingdom Ph.D. studentship (grant number 041/s/16).

\section{ACKNOWLEDGMENTS}

We would like to thank Dr. Barbara Guinn for her helpful discussions.

\section{SUPPLEMENTARY MATERIAL}

The Supplementary Material for this article can be found online at: https://www.frontiersin.org/articles/10.3389/fmicb. 2018.01450/full\#supplementary-material

alkaline protease AprA to prevent flagellin-mediated immune recognition. Infect. Immun. 84, 162-171. doi: 10.1128/IAI.00939-15

Christensen, B. E. (1989). The role of extracellular polysaccharides in biofilms. J. Biotechnol. 10, 181-202.

Chu, H., Khosravi, A., Kusumawardhani, I. P., Kwon, A. H., Vasconcelos, A. C., Cunha, L. D., et al. (2016). Gene-microbiota interactions contribute to the pathogenesis of inflammatory bowel disease. Science 352, 1116-1120. doi: 10 . 1126/science.aad9948

Dalton, T., Dowd, S. E., Wolcott, R. D., Sun, Y., Watters, C., Griswold, J. A., et al. (2011). An in vivo polymicrobial biofilm wound infection model to study interspecies interactions. PLoS One 6:e27317. doi: 10.1371/journal.pone. 0027317

DeLeon, S., Clinton, A., Fowler, H., Everett, J., Horswill, A. R., and Rumbaugh, K. P. (2014). Synergistic interactions of Pseudomonas aeruginosa and Staphylococcus aureus in an in vitro wound model. Infect. Immun. 82, 4718-4728. doi: 10.1128/ IAI.02198- 14

Dengler, V., Meier, P. S., Heusser, R., Berger-Bächi, B., and McCallum, N. (2011). Induction kinetics of the Staphylococcus aureus cell wall stress stimulon in response to different cell wall active antibiotics. BMC Microbiol. 11:16. doi: 10.1186/1471-2180-11-16

Dong, Y.-H., and Zhang, L.-H. (2005). Quorum sensing and quorum-quenching enzymes. J. Microbiol. 43, 101-109.

Dow, G., Browne, A., and Sibbald, R. (1999). Infection in chronic wounds: controversies in diagnosis and treatment. Ostomy Wound Manage. 45, 23-27, 29-40; quiz 41-42.

Drago, L., Vassena, C., Fenu, S., De Vecchi, E., Signori, V., De Francesco, R., et al. (2014). In vitro antibiofilm activity of bioactive glass S53P4. Future Microbiol. 9, 593-601. doi: 10.2217/fmb.14.20

Engel, L. S., Hobden, J. A., Moreau, J. M., Callegan, M. C., Hill, J. M., and O'Callaghan, R. J. (1997). Pseudomonas deficient in protease IV has significantly reduced corneal virulence. Invest. Ophthalmol. Vis. Sci. 38, 1535-1542.

Fleming, D., Chahin, L., and Rumbaugh, K. (2017). Glycoside hydrolases degrade polymicrobial bacterial biofilms in wounds. Antimicrob. Agents Chemother. 61:e01998-16. doi: 10.1128/AAC.01998-16

Flemming, H.-C., and Wingender, J. (2010). The biofilm matrix. Nat. Rev. Microbiol. 8, 623-633. doi: 10.1038/nrmicro2415

Flemming, H.-C., Wingender, J., Szewzyk, U., Steinberg, P., Rice, S. A., and Kjelleberg, S. (2016). Biofilms: an emergent form of bacterial life. Nat. Rev. Microbiol. 14, 563-575. doi: 10.1038/nrmicro.2016.94

Foulston, L., Elsholz, A. K., DeFrancesco, A. S., and Losick, R. (2014). The extracellular matrix of Staphylococcus aureus biofilms comprises cytoplasmic proteins that associate with the cell surface in response to decreasing $\mathrm{pH}$. mBio 5:e1667-14. doi: 10.1128/mBio.01667-14 
Fox, J., and Weisberg, S. (2011). Multivariate Linear Models in R. An $R$ Companion to Applied Regression, 2nd Edn. Thousand Oaks, CA: SAGE.

Gardner, S. E., Hillis, S. L., Heilmann, K., Segre, J. A., and Grice, E. A. (2013). The neuropathic diabetic foot ulcer microbiome is associated with clinical factors. Diabetes Metab. Res. Rev. 62, 923-930. doi: 10.2337/db12-0771

Gellatly, S. L., and Hancock, R. E. (2013). Pseudomonas aeruginosa: new insights into pathogenesis and host defenses. Pathog. Dis. 67, 159-173. doi: 10.1111/ 2049-632X.12033

Gholipourmalekabadi, M., Sameni, M., Hashemi, A., Zamani, F., Rostami, A., and Mozafari, M. (2016). Silver-and fluoride-containing mesoporous bioactive glasses versus commonly used antibiotics: activity against multidrug-resistant bacterial strains isolated from patients with burns. Burns 42, 131-140. doi: 10.1016/j.burns.2015.09.010

Goldner, J. (1938). A modification of the Masson trichrome technique for routine laboratory purposes. Am. J. Pathol. 14, 237-243.

Goodman, A. L., and Lory, S. (2004). Analysis of regulatory networks in Pseudomonas aeruginosa by genomewide transcriptional profiling. Curr. Opin. Microbiol. 7, 39-44.

Gould, L., Abadir, P., Brem, H., Carter, M., Conner-Kerr, T., Davidson, J., et al. (2015). Chronic wound repair and healing in older adults: current status and future research. Wound Repair Regen. 23, 1-13. doi: 10.1111/wrr.12245

Harrison-Balestra, C., Cazzaniga, A. L., Davis, S. C., and Mertz, P. M. (2003). A wound-isolated Pseudomonas aeruginosa grows a biofilm in vitro within 10 hours and is visualized by light microscopy. Dermatol. Surg. 29, 631-635.

Hench, L. L. (2006). The story of Bioglass ${ }^{\circledR}$. J. Mater. Sci. Mater. Med. 17, 967-978.

James, G. A., Swogger, E., Wolcott, R., Secor, P., Sestrich, J., Costerton, J. W., et al. (2008). Biofilms in chronic wounds. Wound Repair Regen. 16, 37-44.

Jones, J. R. (2013). Review of bioactive glass: from Hench to hybrids. Acta Biomater. 9, 4457-4486. doi: 10.1016/j.actbio.2012.08.023

Junqueira, L. C., Bignolas, G., and Brentani, R. (1979). Picrosirius staining plus polarization microscopy, a specific method for collagen detection in tissue sections. Histochem. J. 11, 447-455.

Kalan, L., Loesche, M., Hodkinson, B. P., Heilmann, K., Ruthel, G., Gardner, S. E., et al. (2016). Redefining the chronic-wound microbiome: fungal communities are prevalent, dynamic, and associated with delayed healing. mBio 75:e 0105816. doi: $10.1128 / \mathrm{mBio} .01058-16$

Kallstrom, G. (2014). Are quantitative bacterial wound cultures useful? J. Clin. Microbiol. 52, 2753-2756. doi: 10.1128/JCM.00522-14

Kessler, E., Safrin, M., Gustin, J. K., and Ohman, D. E. (1998). Elastase and the LasA protease of Pseudomonas aeruginosa are secreted with their propeptides. J. Biol. Chem. 273, 30225-30231.

Khosravi, A. D., Shafie, F., Montazeri, E. A., and Rostami, S. (2016). The frequency of genes encoding exotoxin A and exoenzyme S in Pseudomonas aeruginosa strains isolated from burn patients. Burns 42, 1116-1120. doi: 10.1016/j.burns. 2016.02.012

Korgaonkar, A., Trivedi, U., Rumbaugh, K. P., and Whiteley, M. (2013). Community surveillance enhances Pseudomonas aeruginosa virulence during polymicrobial infection. Proc. Natl. Acad. Sci. U.S.A. 110, 1059-1064. doi: 10. 1073/pnas. 1214550110

Lee, J.-Y., Peck, K. R., and Ko, K. S. (2013). Selective advantages of two major clones of carbapenem-resistant Pseudomonas aeruginosa isolates (CC235 and CC641) from Korea: antimicrobial resistance, virulence and biofilm-forming activity. $J$. Med. Microbiol. 62, 1015-1024. doi: 10.1099/jmm.0.055426-0

Leid, J. G., Willson, C. J., Shirtliff, M. E., Hassett, D. J., Parsek, M. R., and Jeffers, A. K. (2005). The exopolysaccharide alginate protects Pseudomonas aeruginosa biofilm bacteria from IFN- $\gamma$-mediated macrophage killing. J. Immunol. 175, 7512-7518.

Lin, C., Mao, C., Zhang, J., Li, Y., and Chen, X. (2012). Healing effect of bioactive glass ointment on full-thickness skin wounds. Biomed. Mater. 7:045017. doi: 10.1088/1748-6041/7/4/045017

Lomholt, J. A., Poulsen, K., and Kilian, M. (2001). Epidemic population structure of Pseudomonas aeruginosa: evidence for a clone that is pathogenic to the eye and that has a distinct combination of virulence factors. Infect. Immun. 69, 6284-6295.

Maçon, A. L., Jacquemin, M., Page, S. J., Li, S., Bertazzo, S., Stevens, M. M., et al. (2017). Lithium-silicate sol-gel bioactive glass and the effect of lithium precursor on structure-property relationships. J. Sol Gel Sci. Technol. 81, 84-94.

Maçon, A. L., Kim, T. B., Valliant, E. M., Goetschius, K., Brow, R. K., Day, D. E., et al. (2015). A unified in vitro evaluation for apatite-forming ability of bioactive glasses and their variants. J. Mater. Sci. Mater. Med. 26, 1-10. doi: 10.1007/s10856-015-5403-9

Mah, T.-F. (2012). Regulating antibiotic tolerance within biofilm microcolonies. J. Bacteriol. 194, 4791-4792.

Maillard, J.-Y., and Hartemann, P. (2013). Silver as an antimicrobial: facts and gaps in knowledge. Crit. Rev. Microbiol. 39, 373-383. doi: 10.3109/1040841X.2012. 713323

Malic, S., Hill, K. E., Hayes, A., Percival, S. L., Thomas, D. W., and Williams, D. W. (2009). Detection and identification of specific bacteria in wound biofilms using peptide nucleic acid fluorescent in situ hybridization (PNA FISH). Microbiology 155, 2603-2611. doi: 10.1099/mic.0.028712-0

Martins, C. H., Carvalho, T. C., Souza, M. G., Ravagnani, C., Peitl, O., Zanotto, E. D., et al. (2011). Assessment of antimicrobial effect of Biosilicate ${ }^{\circledR}$ against anaerobic, microaerophilic and facultative anaerobic microorganisms. J. Mater. Sci. Mater. Med. 22, 1439-1446. doi: 10.1007/s10856-011-4330-7

Mashburn, L. M., Jett, A. M., Akins, D. R., and Whiteley, M. (2005). Staphylococcus aureus serves as an iron source for Pseudomonas aeruginosa during in vivo coculture. J. Bacteriol. 187, 554-566.

Mekkawy, A. I., El-Mokhtar, M. A., Nafady, N. A., Yousef, N., Hamad, M. A., ElShanawany, S. M., et al. (2017). In vitro and in vivo evaluation of biologically synthesized silver nanoparticles for topical applications: effect of surface coating and loading into hydrogels. Int. J. Nanomedicine 12, 759-777. doi: 10.2147/IJN. S124294

Miguez-Pacheco, V., Hench, L. L., and Boccaccini, A. R. (2015). Bioactive glasses beyond bone and teeth: emerging applications in contact with soft tissues. Acta Biomater. 13, 1-15. doi: 10.1016/j.actbio.2014.11.004

Miyajima, S., Akaike, T., Matsumoto, K., Okamoto, T., Yoshitake, J., Hayashida, K., et al. (2001). Matrix metalloproteinases induction by pseudomonal virulence factors and inflammatory cytokines in vitro. Microb. Pathog. 31, 271-281.

Morones-Ramirez, J. R., Winkler, J. A., Spina, C. S., and Collins, J. J. (2013). Silver enhances antibiotic activity against gram-negative bacteria. Sci. Transl. Med. 5:190ra81. doi: 10.1126/scitranslmed.3006276

Munukka, E., Leppäranta, O., Korkeamäki, M., Vaahtio, M., Peltola, T., Zhang, D., et al. (2008). Bactericidal effects of bioactive glasses on clinically important aerobic bacteria. J. Mater. Sci. Mater. Med. 19, 27-32.

Nguyen, A. T., and Oglesby-Sherrouse, A. G. (2016). Interactions between Pseudomonas aeruginosa. Appl. Microbiol. Biotechnol. 100, 6141-6148. doi: 10. 1007/s00253-016-7596-3

O’Neill, J. (2014). Review on Antimicrobial Resistance. Antimicrobial Resistance: Tackling a Crisis for the Health and Wealth of Nations. HM Government. Available at: https://tinyurl.com/yblyrwhm [accessed May 17, 2018].

O’Toole, G. A. (2011). Microtiter dish biofilm formation assay. J. Vis. Exp. 47:2437. doi: $10.3791 / 2437$

Pastar, I., Nusbaum, A. G., Gil, J., Patel, S. B., Chen, J., Valdes, J., et al. (2013). Interactions of methicillin resistant Staphylococcus aureus USA300 and Pseudomonas aeruginosa in polymicrobial wound infection. PLoS One 8:e56846. doi: 10.1371/journal.pone.0056846

Percival, S. L., and McCarty, S. M. (2015). Silver and alginates: role in wound healing and biofilm control. Adv. Wound Care 4, 407-414.

Poologasundarampillai, G., Wang, D., Li, S., Nakamura, J., Bradley, R., Lee, P., et al. (2014). Cotton-wool-like bioactive glasses for bone regeneration. Acta Biomater. 10, 3733-3746. doi: 10.1016/j.actbio.2014.05.020

Posnett, J., and Franks, P. (2008). The burden of chronic wounds in the UK. Diabetic Med. 14, S7-S85.

Price, L. B., Liu, C. M., Melendez, J. H., Frankel, Y. M., Engelthaler, D., Aziz, M., et al. (2009). Community analysis of chronic wound bacteria using 16S rRNA gene-based pyrosequencing: impact of diabetes and antibiotics on chronic wound microbiota. PLoS One 4:e6462. doi: 10.1371/journal.pone.0006462

R Development Core Team (2017). R: A Language and Environment for Statistical Computing. (Version 3.1.1). Vienna: The R Foundation for Statistical Computing.

Randall, C. P., Gupta, A., Jackson, N., Busse, D., and O’neill, A. J. (2015). Silver resistance in Gram-negative bacteria: a dissection of endogenous and 
exogenous mechanisms. J. Antimicrob. Chemother. 70, 1037-1046. doi: 10.1093/ jac/dku523

Rice, K. C., Mann, E. E., Endres, J. L., Weiss, E. C., Cassat, J. E., Smeltzer, M. S., et al. (2007). The cidA murein hydrolase regulator contributes to DNA release and biofilm development in Staphylococcus aureus. Proc. Natl. Acad. Sci. U.S.A. 104, 8113-8118.

Rodriguez-Arguello, J., Lienhard, K., Patel, P., Geransar, R., Somayaji, R., Parsons, L., et al. (2018). A scoping review of the use of silver-impregnated dressings for the treatment of chronic wounds. Ostomy Wound Manage. 64, 14-31.

Rumbaugh, K. P., Griswold, J. A., Iglewski, B. H., and Hamood, A. N. (1999). Contribution of quorum sensing to the virulence of Pseudomonas aeruginosa in burn wound infections. Infect. Immun. 67, 5854-5862.

Ruparelia, J. P., Chatterjee, A. K., Duttagupta, S. P., and Mukherji, S. (2008). Strain specificity in antimicrobial activity of silver and copper nanoparticles. Acta Biomater. 4, 707-716. doi: 10.1016/j.actbio.2007.11.006

Saravanapavan, P., and Hench, L. L. (2001). Low-temperature synthesis, structure, and bioactivity of gel-derived glasses in the binary $\mathrm{CaO}-\mathrm{SiO} 2$ system. J. Biomed. Mater. Res. 54, 608-618.

Schmidtchen, A., Holst, E., Tapper, H., and Björck, L. (2003). Elastase-producing Pseudomonas aeruginosa degrade plasma proteins and extracellular products of human skin and fibroblasts, and inhibit fibroblast growth. Microb. Pathog. 34, 47-55.

Schreml, S., Szeimies, R. M., Karrer, S., Heinlin, J., Landthaler, M., and Babilas, P. (2010). The impact of the $\mathrm{pH}$ value on skin integrity and cutaneous wound healing. J. Eur. Acad. Dermatol. Venereol. 24, 373-378. doi: 10.1111/j.14683083.2009.03413.x

Shigematsu, T., Fukushima, J., Oyama, M., Tsuda, M., Kawamoto, S., and Okuda, K. (2001). Iron-Mediated regulation of alkaline proteinase production in Pseudomonas aeruginosa. Microbiol. Immunol. 45, 579-590.

Siqueira, R. L., Maurmann, N., Burguêz, D., Pereira, D. P., Rastelli, A. N., Peitl, O., et al. (2017). Bioactive gel-glasses with distinctly different compositions: bioactivity, viability of stem cells and antibiofilm effect against Streptococcus mutans. J. Mater. Sci. Eng. C 76, 233-241. doi: 10.1016/j.msec.2017.03.056

Stojadinovic, O., Minkiewicz, J., Sawaya, A., Bourne, J. W., Torzilli, P., de Rivero Vaccari, J. P., et al. (2013). Deep tissue injury in development of pressure ulcers: a decrease of inflammasome activation and changes in human skin morphology in response to aging and mechanical load. PLoS One 8:e69223. doi: 10.1371 /journal.pone.0069223

Stoor, P., Söderling, E., and Salonen, J. I. (1998). Antibacterial effects of a bioactive glass paste on oral microorganisms. Acta Odontol. Scand. 56, 161-165.

Su, H.-L., Lin, S.-H., Wei, J.-C., Pao, I.-C., Chiao, S.-H., Huang, C.-C., et al. (2011). Novel nanohybrids of silver particles on clay platelets for inhibiting silver-resistant bacteria. PLoS One 6:e21125. doi: 10.1371/journal.pone.0021125

Tiwari, V., Tiwari, D., Patel, V., and Tiwari, M. (2017a). Effect of secondary metabolite of Actinidia deliciosa on the biofilm and extra-cellular matrix components of Acinetobacter baumannii. Microb. Pathog. 110, 345-351. doi: 10.1016/j.micpath.2017.07.013

Tiwari, V., Tiwari, M., and Solanki, V. (2017b). Polyvinylpyrrolidone-capped silver nanoparticle inhibits infection of carbapenem-resistant strain of Acinetobacter baumannii in the human pulmonary epithelial cell. Front. Immunol. 16:973. doi: 10.3389/fimmu.2017.00973

Ueno, F. R., Kido, H. W., Granito, R. N., Gabbai-Armelin, P. R., Magri, A. M. P., Fernandes, K. R., et al. (2016). Calcium phosphate fibers coated with collagen: in vivo evaluation of the effects on bone repair. Biomed. Mater. Eng. 27, 259-273. doi: 10.3233/BME-161581

Ushijima, T., Takahashi, M., and Ozaki, Y. (1984). Acetic, propionic, and oleic acid as the possible factors influencing the predominant residence of some species of Propionibacterium and coagulase-negative Staphylococcus on normal human skin. Can. J. Microbiol. 30, 647-652.
Utaida, S., Dunman, P., Macapagal, D., Murphy, E., Projan, S., Singh, V., et al. (2003). Genome-wide transcriptional profiling of the response of Staphylococcus aureus to cell-wall-active antibiotics reveals a cell-wall-stress stimulon. Microbiology 149, 2719-2732.

Van der Waal, S., Van der Sluis, L., Özok, A., Exterkate, R., van Marle, J., Wesselink, P., et al. (2011). The effects of hyperosmosis or high $\mathrm{pH}$ on a dual-species biofilm of Enterococcus faecalis and Pseudomonas aeruginosa: an in vitro study. Int. Endod. J. 44, 1110-1117. doi: 10.1111/j.1365-2591.2011.0 1929.x

Velnar, T., Bailey, T., and Smrkolj, V. (2009). The wound healing process: an overview of the cellular and molecular mechanisms. J. Int. Med. Res. 37, 1528-1542.

Weinrick, B., Dunman, P. M., McAleese, F., Murphy, E., Projan, S. J., Fang, Y., et al. (2004). Effect of mild acid on gene expression in Staphylococcus aureus. J. Bacteriol. 186, 8407-8423.

Wiens, J. R., Vasil, A. I., Schurr, M. J., and Vasil, M. L. (2014). Iron-regulated expression of alginate production, mucoid phenotype, and biofilm formation by Pseudomonas aeruginosa. mBio 5:e01010-13. doi: 10.1128/mBio.01010-13

Wilkinson, H. N., McBain, A. J., Stephenson, C., and Hardman, M. J. (2016). Comparing the effectiveness of polymer debriding devices using a porcine wound biofilm model. Adv. Wound Care 5, 475-485.

Wolcott, R. D., Hanson, J. D., Rees, E. J., Koenig, L. D., Phillips, C. D., Wolcott, R. A., et al. (2015). Analysis of the chronic wound microbiota of 2,963 patients by $16 \mathrm{~S}$ rDNA pyrosequencing. Wound Repair Regen. 24, 163-174. doi: 10.1111/ wrr. 12370

Wu, C., Chang, J., and Xiao, Y. (2017). "Bioactive scaffolds with multifunctional properties for hard tissue regenerations," in Biomaterials for Implants and Scaffolds, eds Q. Li and Y.-W. Mai (Berlin: Springer), 371-388.

Yeung, C. C., Holmes, D. F., Thomason, H. A., Stephenson, C., Derby, B., and Hardman, M. J. (2016). An ex vivo porcine skin model to evaluate pressurereducing devices of different mechanical properties used for pressure ulcer prevention. Wound Repair Regen. 24, 1089-1096. doi: 10.1111/wrr.12481

Zehnder, M., Waltimo, T., Sener, B., and Söderling, E. (2006). Dentin enhances the effectiveness of bioactive glass S53P4 against a strain of Enterococcus faecalis. Oral Surg. Oral Med. Oral Pathol. Oral Radiol. Endod. 101, 530-535.

Zhang, S., Ye, C., Lin, H., Lv, L., and Yu, X. (2015). UV disinfection induces a VBNC state in Escherichia coli and Pseudomonas aeruginosa. Environ. Sci. Technol. 49, 1721-1728.

Zhao, S., Li, L., Wang, H., Zhang, Y., Cheng, X., Zhou, N., et al. (2015). Wound dressings composed of copper-doped borate bioactive glass microfibers stimulate angiogenesis and heal full-thickness skin defects in a rodent model. Biomaterials 53, 379-391. doi: 10.1016/j.biomaterials.2015.02.112

Zoeiby, A., Sanschagrin, F., Havugimana, P. C., Garnier, A., and Levesque, R. C. (2001). In vitro reconstruction of the biosynthetic pathway of peptidoglycan cytoplasmic precursor in Pseudomonas aeruginosa. FEMS Microbiol. Lett. 201, 229-235.

\section{Conflict of Interest Statement: PC is the CEO of Theraglass ${ }^{\mathrm{TM}} \mathrm{Ltd}$.}

The remaining authors declare that the research was conducted in the absence of any commercial or financial relationships that could be construed as a potential conflict of interest.

Copyright (c) 2018 Wilkinson, Iveson, Catherall and Hardman. This is an open-access article distributed under the terms of the Creative Commons Attribution License (CC BY). The use, distribution or reproduction in other forums is permitted, provided the original author(s) and the copyright owner(s) are credited and that the original publication in this journal is cited, in accordance with accepted academic practice. No use, distribution or reproduction is permitted which does not comply with these terms. 